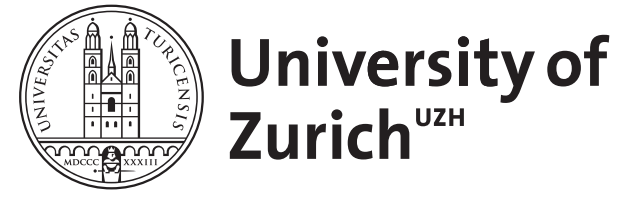

Zurich Open Repository and Archive

University of Zurich

University Library

Strickhofstrasse 39

CH-8057 Zurich

www.zora.uzh.ch

Year: 1995

In the vestibule of meaning: transitivity inversion as a morphological phenomenon

Bickel, Balthasar

DOI: https://doi.org/10.1075/sl.19.1.04bic

Posted at the Zurich Open Repository and Archive, University of Zurich ZORA URL: https://doi.org/10.5167/uzh-76703

Journal Article

Originally published at:

Bickel, Balthasar (1995). In the vestibule of meaning: transitivity inversion as a morphological phenomenon. Studies in Language, 19:73-127.

DOI: https://doi.org/10.1075/sl.19.1.04bic 


\title{
IN THE VESTIBULE OF MEANING:
}

TRANSITIVITY INVERSION

\section{AS A MORPHOLOGICAL PHENOMENON}

\author{
BALTHASAR BICKEL \\ Max-Planck-Research Group in Cognitive Anthropology Nijmegen, \\ Tribhuvan University, Kìrtipur, Kāthmānḍ̂̄, \\ University of Zürich
}

\section{ABSTRACT}

In the Belhare (Tibeto-Burman) verb, morphotactics and allomorphy, but not morpheme semantics, are sensitive to a distinction between direct $(1>2,1>3,2>3$, $3 \mathrm{SG}>3$ ) and inverse ( $3 \mathrm{NS}>3,3>2,3>1,2>1)$ participant configurations. Comparison of this phenomenon with Cree (Algonquian) and rGya-ron (Tibeto-Burman) calls for a distinction of morphemic and sub- or supra-morphemic inversion. The difference is semiotically interpreted in a general theory of "Resonance Morphology". The smallest resonant pattern is either compositional and meaningful, i.e. a "morpheme", or predictable and meaningless, i.e. an "eideme". Eidemes can be motivationally grounded in an extra-morphological domain (e.g. pragmatics). This is demonstrated for morphotactics and allomorphy in Belhare and for a parallel in French.

\section{Humboldt's problem}

It is always a delight to read how Wilhelm von Humboldt discussed topics which are now of current linguistic interest. One of these topics is transitivity inversion in Algonquian languages (Humboldt 1836: 189f). The verbal conjugation of the Massachusett language struck him by a curious 
phenomenon of morphotactic structure. Illustrated with a literal translation in German (1), Humboldt gives the following rule: If a second person acts on a first person, the sign of the first person gets suffixed, as in (1a). If it is a third person that acts on the first, however, the first is prefixed (1b). (2) supplies real Massachusett examples (Goddard and Bragdon 1988: 520ff): ${ }^{1}$

a. du-greifst-mich

(2)

a. ksw-adchan-eh.
2-keep-2SG $>$ 1SG

'Thou keepest me.' b. mich-greift-er

b. nu-ttunn-uk.

1-say-INV

'He said to me.'

In both verb forms the participant configuration or "scenario" is fully determined by the individual morphemes. In (2a) the suffix - eh stands for a second person singular acting on a first person singular. In the $(2 b)$ form the inverse marker defines the transitivity direction by pointing to an actor who is lower than the referent of $n u$ - ' 1 ' on the Algonquian referential hierarchy: $2 / 1>3$ proximative $>3$ obviative. (It seems that Humboldt mistook the markers for a first undergoer and a third actor, respectively, but this is immaterial to my immediate discussion.)

The question is: why should the morpheme $e h$ be a suffix and $n u$ a prefix despite the fact that they are clearly distinguished by their sound shape alone? Apparently, there is a striking case of redundancy. A similar phenomenon can be observed in Belhare, a Tibeto-Burman language of the Kiranti group spoken in Eastern Nepal. Consider the expressions in (3). ${ }^{2}$
a. lapbhettum. lap-het- $t$ - $\boldsymbol{u}-\boldsymbol{m}$ catch-IPFV-NPT-3U-1PL:A 'Weip are catching him.'

b. kaylapbhet. ka- $\boldsymbol{y}$-lap-het- $t$ I:U-3NS:A-catch-IPFV-NPT 'They are catching us'.'

The meaning of the morphemes used in these forms exhaustively determines the overall meaning of the two expressions. It seems rather luxurious and redundant to further differentiate the inflectional affixes morphotactically, that is to suffix in one case, and to prefix in the other.

In what follows, I shall first outline the relevant facts about Belhare verb inflection (Section two). In particular, I shall argue that the semantic structure of verb inflection in this language is entirely built on the categories "reference" (including three persons and three numbers) and "role" (including "intransitive subject" as well as "actor" and "undergoer" in the sense of 
'generalized semantic relations' (Foley and Van Valin 1984: 29)). Against this background, the morphological peculiarity to which example (3) alludes, is captured by a notion of supramorphemic transitivity inversion that contrasts with classical phenomena of morphemic transitivity inversion as described e.g. by Hockett (1966), Heath (1976) or DeLancey (1981) (Section three). In order to explore supramorphemic inversion ${ }^{3}$ further, its semiotic status in grammar will be discussed in Section four. I shall set up a theory of "Resonance Morphology" that starts from a general notion of smallest recurrent pattern which is subdivided into compositional, meaningful patterns (viz. "morphemes") and predictable, meaningless patterns. For the latter I shall introduce the notion "eideme". Eidemes may or may not be motivated (in a sense to be specified). Supramorphemic inversion is evaluated as an instance of a motivated eideme. A typological parallel in French shows that eidemic inversion may also be submorphemic (Section five). Section six summarizes the findings and completes the comparison of eidemic and morphemic inversion.

Throughout the paper, I use the term "semantics" in the sense of Wierzbicka (1988), i.e. not as a domain in opposition to morphology and syntax but as the study of conventional meaning of both morphological units and syntactic constructions.

\section{Semantic structure of Belhare verb forms}

Belhare is a typical representative of what has been known by TibetoBurman linguists since Hodgson (1856) as a "pronominalized" language. Drawing on similar inflectional resources as nouns and pronouns, verbal morphology cross-indexes intransitive subject and, in transitive verbs, both actor and undergoer. The actor is the most agentive argument indexed by a transitive predicate whereas the undergoer is the least agentive argument and is often, depending on the verb's valency, rather a beneficiary than a patient (cf. van Driem (1991) for a typological perspective on this phenomenon). The clausal arguments themselves appear optionally as nouns or free pronouns. Case marking follows a split-ergative pattern with first person singular actors remaining in the unmarked absolutive. The charts in Table 1 and 2 show intransitive and transitive inflection, respectively. Paradigm order is computed in agreement with the traditional principle that forms that are neigh- 
bours are those that can formally converge (cf. Plank 1991b). The symbol $\Sigma$ stands for a verbal stem form. What I write with a superscribed capital $N$ is a floating nasality feature that associates with a preceding coda consonant or coda slot. In isolation, the feature generates a syllable of its own, yielding a syllabic nasal. Place of articulation is regressively spread, but restricted to a $/ \mathrm{n} / \sim / \mathrm{y} /$ alternation when filling an empty coda position.

The forms in Table 1 and 2 attach to (combinations of) verb stems and one or more tense/aspect/mood (henceforth TAM) suffixes. There is, in contrast to other Kiranti languages (e.g. Limbu, cf. van Driem 1987 or Camling, cf. Ebert 1990), no intermingling of role and reference with TAM beyond general morphophonology (e.g. rules deleting $-u$ ' $3 U$ ' when adjacent to an /e/-final TAM-suffix). We can, therefore, more or less directly extract the morphemes from Table 1 and 2 (cf. Table 3). General rules that affect the paradigm are progressive place of articulation spreading with nasals and a contraction rule deleting $/ \mathrm{i} /$ and $/ \mathrm{a} /$ before $/ \mathrm{u} /$. The abundance of nasals results from a rule that regressively copies single nasal morphs around any syllable if following an /a/-final TAM-suffix and around -chi 'NS:A/U' elsewhere.

Table 1. Belhare intransitive verb inflection

\begin{tabular}{llll}
\hline & SG & PL & DL \\
\hline Excl. & $-\eta a$ & $-i-\eta a$ & $-c h i-\eta a$ \\
Incl. & & $-i$ & $-c h i$ \\
2 & $-g a$ & $-i-g a$ & $-c h i-g a$ \\
3 & $-\phi$ & $N-\sum-\phi$ & $N-\sum-c h i$ \\
\hline
\end{tabular}

Table 2. Belhare transitive verb inflection

\begin{tabular}{|c|c|c|c|c|c|c|c|c|}
\hline AlU & 1SG & E:NS & I:NS & $2 \mathrm{SG}$ & $2 \mathrm{PL}$ & $2 \mathrm{DL}$ & 3SG & $3 \mathrm{NS}$ \\
\hline 1SG & & & & $-n a$ & $-n a n-i$ & -na-chi & $-u-\eta$ & $-u-\eta-c h i-\eta$ \\
\hline E:PL & & & & & -na-chi-na & & $-u-m-m a$ & $-u-m-c h i-m-m a$ \\
\hline E:DL & & & & & & & -ch-u-na & \\
\hline I:PL & & & & & & & $-u-m$ & $-u-m-c h i-m$ \\
\hline I:DL & & & & & & & $-c h-u$ & \\
\hline $2 \mathrm{SG}$ & $k a-\Sigma-g a$ & $m a 7 i-\Sigma-g a$ & & & & & $-u-g a$ & -u-chi-ga \\
\hline $2 \mathrm{PL}$ & $k a-\Sigma-i-g a$ & $m a ? i-\Sigma-i-g a$ & & & & & $-u-m-g a$ & $-u-m-c h i-m-g a$ \\
\hline $2 \mathrm{DL}$ & $k a-\Sigma-c h i-g a$ & ma?i-L-chi-g & & & & & $-c h-u-g a$ & \\
\hline $3 \mathrm{SG}$ & mai- & ma?i- & $k a-$ & $N_{-\Sigma}-g a$ & $N-\Sigma-i-g a$ & $N_{-}-$-chi-ga - & & $-u-c h i$ \\
\hline 3PL & $m a-\eta$ & & $k a-\eta$ & & & & $N_{-\Sigma}-u$ & $N-\Sigma-u-c h i$ \\
\hline $3 \mathrm{DL}$ & $m a-\eta-\Sigma-c h i$ & $m a ? i-\Sigma-c h i$ & $k a-\eta-\Sigma-c h i$ & & & & $N-\Sigma-c h-u$ & \\
\hline
\end{tabular}


Table 3. Slot display of role and reference inflection in Belhare

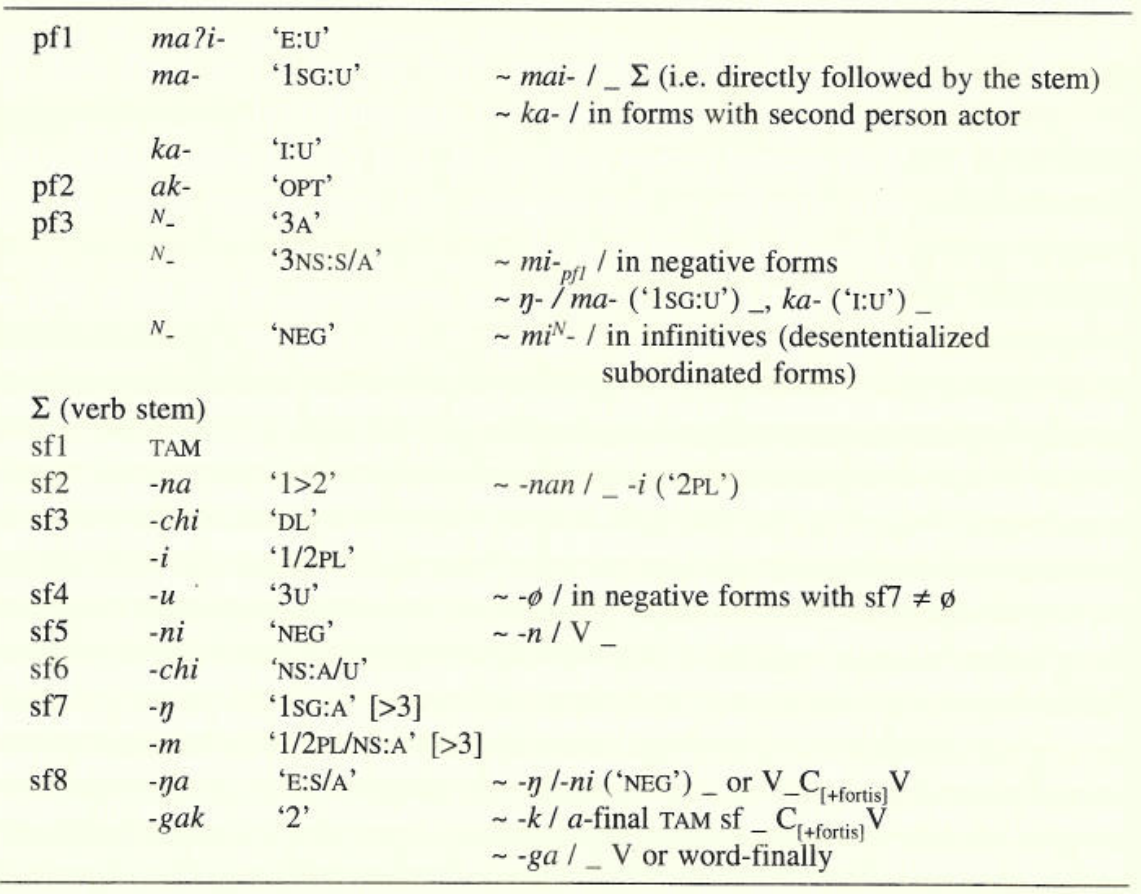

Transitives inflect for three numbers of both actor and undergoer except in the following cases. A first or third person undergoer distinguishes only singular from non-singular. Another number neutralisation in undergoers is triggered by the nature of the actor category:

(4) With first person non-singular actors, the number of second person undergoers is not distinguished.

Curiously, in this configuration the morpheme -chi 'NS:A' appears together with - $y a$ 'E:A' ('exclusive', i.e. the actor including [+speaker -addressee]), a fact looking suspiciously like redundancy. However, indicating number here is crucial for Belhare because the language does allow for an 'exclusive singular'. This is in fact the way the so-called first person is construed in intransitive forms (for a similar phenomenon in pronouns of nearby Limbu, see van Driem (1987: 28)). 
Number neutralisations in actors are defined by the nature of the undergoer (5).

(5) a. With exclusive undergoers, third person actors mark dual in opposition to undifferentiated singular/plural.

b. With second person undergoers, first person actors distinguish only singular vs. non-singular, and third person actors do not differentiate number at all.

c. With third person non-singular undergoers, actors show only a binary distinction of singular vs. non-singular.

Due to the neutralisation rule (5a), the sign for third person non-singular actors $\left({ }^{N_{-}}\right)$may not combine with ma ?i- 'E:U'. All other co-occurrence restrictions follow from semantic incompatibility, slot distribution or selectional restrictions. The latter are represented in Table 3 by square brackets. For instance $-\eta^{\prime} 1$ SG:A' is only used with third person undergoers, otherwise -na ' $1>2$ ' is the appropriate suffix.

A widespread characteristic of Belhare inflectional morphemes is polysemy. Thus, for instance, the morpheme $-m$ covers first plural actors, second plural actors, first non-singular actors and second non-singular actors. The meanings are immediately clarified by the morphemic environment in which the sign appears:

(6)
a. luitum.
lu- $t-u-m$
tell-NPT-3U-(1PL:A)
'Wepi tell him.'
c. luitumga.
lu- $t$ - $u-m-g a$
tell-NPT-3U-(2PL:A)-2
'Youp tell him.'

b. luitumchim.

lu- $t$ - $u-c h i-m$

tell-NPT-3U-NS:U-(1NS:A)

'Wensi tell them.'

d. luitumchimga. lu-t-u-chi-m-ga tell-NPT-3U-NS:U-(2NS:A)-2

'Youns tell them.'

Such processes of disambiguation are indicated in (6) by putting an interlinear gloss in brackets. The criterion on which to decide whether a morpheme is polysemeous or semantically uniform (i.e. showing a Gesamtbedeutung) is strictly based on potentials for ambiguity resolution (cf. Bickel 1991a: 16ff). A morpheme is semantically uniform if it cannot be resolved into smaller units by conventional linguistic means (but only by situational aspects). This 
claim, while perhaps intuitively uncontroversial, has a strong impact on the range of semantic categories that may be validly postulated in a given language. By this standard, there is, for instance, no ground on which - $m$ could be glossed as a number sign for the unitary category 'speech act participant'.

As a more intricate problem let us consider ${ }^{N_{-}}$and its allomorphs. This morpheme indicates not only third person non-singular subjects in intransitives but also appears in some transitive forms. The sign ${ }^{N_{-}}$is homophonous with a negation prefix that is used in intransitives and in $1>2,1>3,2>3$ and $3>3$ scenarios. At first sight, there are two ways of analysing the function of non-negative $N_{-}$in transitives. The crucial forms are the affirmative and negative versions of transitive inflection. Table 4 exemplifies them with the verb luma 'to tell'. 4

On the first possible account, ${ }^{N_{-}}$is analysed as an inverse marker restricted to scenarios without a first person involved. ${ }^{5}$ This notion tries to overcome the impossibility of unifying the fact that ${ }^{N}$ - covers any third person actor with a second person undergoer and the peculiarity that it is restricted to non-singular actors. with a third person undergoer. The corollary of this account is that $m i$ - needs to be regarded as an allomorph of $N_{-}$'NEG' triggered by a phonological constraint on a sequence of two floating nasals $\left(* N_{-} N_{-}\right)$. Notice that $m i$ - cannot be analysed as an allomorph of the inverse marker because this would violate the principle of complementary distribution. We would, instead, get an allomorph pair ${ }^{N_{-}} \sim m i$ - for third person non-singular actors only, and a single ${ }^{N}$-morph representing third person actors without number restriction. Yet this is the second way of analysis, viz. to assume two morphemes, one, ${ }^{N_{-}} \sim m i-$, meaning ' $3 \mathrm{NS}_{\mathrm{A}} \mathrm{A}$ ' and the other, ${ }_{-}$, meaning ' $3 \mathrm{~A}$ '.

\section{Table 4. Belhare transitive inflection (section)}

\begin{tabular}{lll}
\hline 3SG $>$ 3SG & luitu & nluitun \\
3SG>3NS & luituchi & nluitunchin \\
3PL>3SG & nluitu & minluitun \\
3DL>3SG & nluichu & minluichun \\
3NS>3NS & nluituchi & minluitunchin \\
3 $>2 \mathrm{SG}$ & nluika & nlui?niga \\
3>2PL & nluitiga & nluitinga \\
3>2DL & nluichiga & nluichinga \\
3DL $>1 \mathrm{SG}$ & mayluichi & mayluichin \\
3DL $>\mathrm{E}$ & ma?iluichi & ma?iluichin \\
& Affirmative & Negative \\
\hline
\end{tabular}


This analysis gains a lot in plausibility when we take more distributional facts into account. First, the intransitive use of $N_{-} \sim m i$ - for third non-singular subjects is easily integrated into the polysemy structure of the morpheme, yielding '3NS:S/A':

$$
\begin{aligned}
& \text { a. } \quad \text { jkharechi. } \\
& N_{-k h a t-}{ }^{h} e-c h i \\
& \text { 3NS:S-go-PT-DL } \\
& \text { 'They }{ }^{d} \text { went.' }
\end{aligned}
$$

b. nkhare. ${ }^{N}$-khat ${ }^{h} e$

3NS:S-go-PT

'Theyp went.' c. minkhatdatchin. $m i{ }^{N}-k h a t-a t t-c h i-n i$ 3NS:S-[-go-PT-DL-NEG] 'They did not go.'

Such a convergence of categories is evidently more plausible than a conflation of ' $3 N S$ ' and 'INV'. Furthermore, the non-assimilating $-\eta$ - formative, which indicates a third person non-singular actor in $3>1$ scenarios (cf. Table 2) could be treated as yet another allomorph of ' $3 \mathrm{NS}: \mathrm{S} / \mathrm{A}$ ' (8a). In optative forms, i.e. when not immediately following the prefix slot one fillers ma'1sG:U' or ka- 'I:U' (cf. Table 3), the morpheme shows up, indeed, as a floating nasal associating to the preceding $/ \mathrm{k} /$ in the optative prefix $a k$ - (8b). In this environment it is, therefore, not only semantically but also formally identical to ${ }^{N_{-}}$' $3 \mathrm{NS}: \mathrm{A}$ ' $(8 \mathrm{c})$.

a. mayluichi.

$m a-\boldsymbol{y}-l u-t-c h i$

1SG:U-3NS:A-tell-NPT-DL

'They ${ }^{\mathrm{d}}$ tell me.'

b. maayluchin.

$m a-a k^{-}{ }^{N}-l u-c h i-n i$

1SG:U-OPT-3NS:A-tell-DL-NEG

'They shouldn't tell me.' c. ayluruchi.

$a$-N $^{N}$ lur-u-chi

OPT-3NS:A-tell-3U-NS:U

'They should tell them.'

Along with $m a-$ ('1SG:U'), $k a-$ ('I:U') and $m a ? i$ - ('E:U'), the $m i$ - allomorph also precedes the optative marker:

(9) miaylurun.

$m i-a k^{-N}-l u r-u-n i$

3NS:A-OPT-[-tell-3U-NEG]

'They shouldn't tell him.'

This morphotactic behaviour is plausible if $m i$ - is treated as an allomorph of the ' $3 \mathrm{NS}: \mathrm{A}$ ' morpheme rather than as a negation sign: the first prefix position 
is semantically consistent in so far as it contains, in contrast to other prefix slots, only role and reference markers.

Allegedly, this kind of evidence may well validate an analysis. But it cannot replace arguments for an analysis. These reside entirely in semantics. And here, we have to take into account that ${ }^{N}$ - is clearly disambiguated by its morphological environment. The sign means ' $3 \mathrm{NS}: \mathrm{A}$ ' in the context of $-u$ ' $3 \mathrm{U}$ ' and ' $3 \mathrm{~A}$ ' in the context of $-g a$ ' 2 '. The morpheme $-g a$ itself, while as a morpheme it is not specified for role, has always an unequivocal reading that is established independently from ${ }^{N_{-}}$. In transitives, it refers to a second person actor after $-u$ ' $3 \mathrm{U}$ ', $k a$ - '1SG:U' and ma? $i$ - 'E:U'and to an undergoer elsewhere.

The same kind of semantic scrutiny applies to morphemes that are wordinternally underspecified. We have seen that $-m$ resolves into the readings '1PL:A', '1NS:A', '2PL:A' and '2NS:A'. As for non-singular, however, there is no word-internal cue to decide whether $-m$ refers to two or more actors. This becomes clear only when pronouns come into play:
a. hanchikya
unchik lurhemchimga.
han-chik- ja
un-chik
lur- ${ }^{h} e-u-c h i-m-g a$
2-DL-ERG 3-NS
tell-PT-3U-NS:U-2NS:A-2
'You ${ }^{\mathrm{d}}$ told them.'
b. hanikna
unchik
lurhemchimga.
han-ik-ya
un-chik
lur- ${ }^{h} e-u-c h i-m-g a$
2-PL-ERG 3-NS
tell-PT-3U-NS:U-2NS:A-2
'Youp told them.'

The difference between the first and the second kind of polysemy is that in the former case polysemy is obligatorily resolved whereas in the latter case resolution is optional. ${ }^{6}$ We may distinguish the two kinds of polysemy by using abbreviated glosses for polysemeous signs that are only optionally resolved, for example 'non-singular' vs. 'dual/plural'. A similar kind of abbreviation is useful with portemanteau morphemes. Bear in mind, however, that a gloss like ' $1>2$ ' for -na does not stipulate a semantic category of transition. ${ }^{7}$ Rather, ' $1>2$ ' is simply a short-hand expression for 'first person actor and second person undergoer'. These categories, but not 'transition' ('>'), may show up individually with pronouns, i.e. it is these categories that are the actual building blocks of Belhare semantics. 
When these methodological remarks are taken into account, the semantic structure of Belhare inflectional morphemes becomes straightforward: all participant configurations are encoded by designating person, number and role. The respective signs do this exhaustively in most cases. With some configurations, verb forms are still polysemous about number. This polysemy is resolvable by pronouns ${ }^{8}$ or, indeed, numerals.

\section{Supramorphemic inversion vs. morphemic inversion}

Although the morpheme analysis carried out in the preceding section gives insight into the semantic make-up of Belhare verb forms, it misses important generalizations of a purely morphological kind. Looking at the whole paradigm of transitive inflection as laid out in Table 2, we detect an interesting pattern in morphotactics. Affix position divides transitive forms into two classes as shown in Table 5. Notice that the difference in affix position in no way adds anything to the meaning of the forms. Position is fully predictable from the meaning of the morphemes involved. It is, thus, truly redundant. Yet it follows a well-defined pattern reminiscent of direct vs. inverse oppositions (cf. Ebert 1991: 86).

Table 5. Belhare affix position

\begin{tabular}{|c|c|c|}
\hline & $\begin{array}{l}\text { Forms without prefixes: } \\
1>2 \\
1>3 \\
2>3 \\
3 \text { SG }>3\end{array}$ & $\begin{array}{l}\text { Forms with prefixes: } \\
2>1 \\
3>1 \\
3>2 \\
3 \text { NS }>3\end{array}$ \\
\hline \multirow[t]{2}{*}{ E.g. } & $\begin{array}{l}\text { a. lapbhetna } \\
\text { lap-het- } t \text {-na } \\
\text { catch-IPFV-NPT-1>2 } \\
\text { 'I am catching you.' }\end{array}$ & $\begin{array}{l}\text { b. kalapbhetka } \\
\text { ka-lap-het-t-ga } \\
\text { 1SG:U-catch-IPFV-NPT-2 } \\
\text { 'You are catching me.' }\end{array}$ \\
\hline & 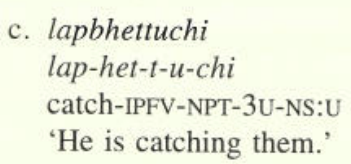 & $\begin{array}{l}\text { d. nlapbhettu } \\
N_{\text {-lap-het- } t \text { - } u} \\
\text { 3NS:A-catch-IPFV-NPT-3U } \\
\text { 'They are catching him.' }\end{array}$ \\
\hline
\end{tabular}


Following DeLancey $(1980,1981)$ direct situations are those where viewpoint and referential starting point (in his "linguistic attention flow") coincide, inverse situations are those where they differ. The referential starting point in Belhare transitive scenarios is the actor, as evidenced by the following. In connected discourse, Belhare syntax treats actors, but not undergoers like subjects. The language shows in most constructions nominativeaccusative syntax; connected discourse monitors, in Foley and Van Valin's (1984) terms, $\{\mathrm{S}, \mathrm{A}\}$-pivots rather than $\{\mathrm{s}, \mathrm{U}\}$-pivots.

For instance, with the same reference marker $-s a$, it is syntactically not possible to have the story teller as the one who is freed from lice (11a). That is, the actor of the first clause cannot be coreferent with the undergoer of the subsequent clause. This rule is violated in (11b): the actor of chissa 'meeting' cannot be resumed as an undergoer $\left(-u\right.$ ' $\left.3 \mathrm{U}^{\prime}\right)$ in the second clause. Also the coreference of the actor of the second clause ( $-g a$ ' 2 ') with the preceding undergoer (i.e., the implicit second person undergoer of chissa "meeting') does not license the use of $-s a$. Therefore, $-s a$ is glossed 'same subject'. 9

(11) a. kntha massa unna un sik setpiyakt ${ }^{h}$ e.

$k n$ tha mat-sa un-ya un sik set-pi-yakt- ${ }^{h} e-u$

story tell-ss 3-ERG 3 louse kill-BEN-IPFV-PT-3U

'She was delousing her when telling a story.'

b. *unna chissa yeti luituga?

un-ya chit-sa yeti lu-t-u-ga

3-ERG find-ss what tell-NPT-3U-2

'What will you say to him when he finds you?'

To convey the message (11b) tries to encode, a subordinate construction with the topic marker $-n a$ is used (12a).

(12) a. unna nchitgakna yeti luituga?

un-ya ${ }^{N}$-chit-gak-na yeti lu-t-u-ga

3-ERG 3A-find-2-TOP what tell-NPT-3U-2

'When he finds you, what will you say to him?'

b. ma?ina kubay nisuna pi isa khatcahe.

ma?i-na kubay nis-a-u-na pin-sa khat-ca- ${ }^{h} e$ human-ERG monkey see-CONJ:PT-3U-TOP run-SS go-TEL-PT 'When the man $_{i}$ saw the monkey, he ${ }_{i}$ ran away.' 
The subordinator -na is not semantically restricted to coreference, but zero anaphora again monitors a $\{\mathrm{S}, \mathrm{A}\}$ pivot: $(12 \mathrm{~b})$ cannot be interpreted in such a way that it is the monkey who ran away. This syntactic constraint motivated heavy protest against and a good deal of amusement about the sentence by those consultants who did not judge it on a metalinguistic level. It is indeed bad for a man to run away instead of chasing away the monkey (who is a serious danger for maize crops). The ubiquity of $\{\mathrm{S}, \mathrm{A}\}$-pivots points to referential prominence of the actor rather than to great import of the undergoer. ${ }^{10}$

If actors are referentially more prominent than undergoers, affix position in the verbal paradigm can be accounted for by the following rule: prefixes appear exactly in those cases where the relatively prominent actor is lowest on the hierarchy (13) or lower than the relatively non-prominent undergoer.

\section{(13) $1>2>3$ SG $>3$ NS}

The hierarchy is governed by referential closeness to the speaker or empathy (Kuno 1987). If we assume viewpoint in Belhare to be driven by this hierarchy, prefixation is motivated by a mismatch of viewpoint and referential prominence. Such a mismatch is called "inverse".

What is methodologically even more important, is that the distinction between "direct" and "inverse" is crucial for allomorphy distribution in negative forms. There is no negative prefix in $2>1,3>1$ and $3>2$ scenarios. Thus, we can complete our account in Table 3 by formulating the following rule.

$$
\begin{aligned}
N_{-} \sum-n(i) \text { 'NEG' } \sim-n(i) / & \text { in scenarios that are inverse on the } \\
& \text { hierarchy (13) above 3SG } \\
\sim m i^{N}-/ & \begin{array}{l}
\text { in infinitives (desententialized subordi- } \\
\text { nated forms) }
\end{array}
\end{aligned}
$$

Notice that it is not possible to define the environment by simple absence of a prefix, because ${ }^{N}-\Sigma-n(i)$ occurs in third person non-singular forms where it triggers the $m i$ - allomorph for person reference:

(15) a. minkhatdatni. $m i-{ }^{N}-k h a t-a t t-n i$

3NS:S-[-go-PT-NEG]

'Theyp did not go.' b. minluattun. $m i^{-}{ }^{N}-l u-a t t-u-n i$ 3NS:A-[-tell-PT-3U-NEG] 'Theyp did not tell him.' 
Consequently, Belhare morphology is sensitive to the distinction of direct vs. inverse although these categories do not participate in the semantic structure of the morphemes involved and are entirely redundant. To further appreciate the peculiarity of this phenomenon, we may compare Belhare to one of the languages to which the notions "inverse" and "direct" were first applied, viz. to languages of the Algonquian family (Hockett 1966).

\subsection{What morphemic inversion is really like: Plains Cree}

As a representative example of Algonquian inversion, I shall discuss conjugation in the Plains dialect of Cree (cf. Wolfart 1973, 1978 and Dahlstrom 1986). Tables 6 and 7 provide a display of verbal slots and their morpheme fillers. There is an over-all distinction of 'independent' (Table 6) and 'conjunct' (Table 7) inflection, which has to do with subordination. (The precise nature of the distinction is immaterial to our immediate interests.) Besides the slots presented here there is a further prefix position used for some sorts of nominal and verbal determination (see Dahlstrom 1986: 18ff). I have changed Dahlstrom's presentation on some points where it appears to me that an easier generalisation on morpheme distribution can be made. As in Belhare, I use selectional restrictions (in square brackets) to indicate cooccurrence restrictions across slots. Exclusive is again the category [+speaker -addressee] (cf. Hockett 1966: 68) and refers exclusively to the speaker when put into the singular (cf. Belhare). Chart 7 for conjunct inflection shows some important differences in suffix position two, five and seven. There is, in

Table 6. Slot display of Plains Cree independent inflection

\begin{tabular}{|c|c|c|c|c|c|c|c|}
\hline $\begin{array}{l}\text { pf } \\
\text { person }\end{array}$ & $\begin{array}{l}\text { sfl } \\
\text { obviation }\end{array}$ & $\begin{array}{l}\text { sf2 } \\
\text { 'theme' }\end{array}$ & $\begin{array}{l}\text { sf3 } \\
\text { obviation }\end{array}$ & $\begin{array}{l}\text { sf4 } \\
\text { TM }\end{array}$ & $\begin{array}{l}\text { sf5 } \\
\text { person/number }\end{array}$ & $\begin{array}{l}\mathrm{sf6} \\
\mathrm{TM}\end{array}$ & $\begin{array}{l}\text { sf7 } \\
\text { plural/obviation }\end{array}$ \\
\hline $\begin{array}{l}\text { ki- kit-'2' } \\
n i-\sim n i t-' \mathrm{E} \text { ' } \\
o-\sim o t-' 3 \text { ' [P }\end{array}$ & -im 'DIR' & $\begin{array}{l}-a: \text { 'DIR' } \\
-e: \text { '3DIR' } \\
-i k w \sim-i k o \\
-i \text { ' } 2>1 \text { ' } \\
-i t i \text { '1>2' } \\
-e: \text { 'TR' / } \\
\sim-a m / \text { I } \\
\sim-a: / \text { IN } \\
\sim-\phi / \text { INA }\end{array}$ & $\begin{array}{l}-i y i \text { 'OBV' } \\
\quad \sim-\phi / E / I / 2 \\
\text { 'INV' } \\
\text { I/2 INAN (i) } \\
\text { NAN (i) } \\
\text { AN (ii) } \\
\text { N (iii) }\end{array}$ & & $\begin{array}{l}\text {-na:n 'E' } \\
\text {-na:naw -naw ' } 1 \text { ' } \\
\text {-na:wa:w -wa:w } \\
-n \text { '1/2 SG/1SG\&2 } \\
-w \text { '3' }\end{array}$ & 2PL' & $\begin{array}{l}-a k^{\prime} 3 \mathrm{PL} \text { '[ANIM:PROX] } \\
-a \text { 'OBV' [ANIM] } \\
-a \text { '3PL' [INAN] }\end{array}$ \\
\hline
\end{tabular}


Table 7. Slot display of Plains Cree conjunct inflection

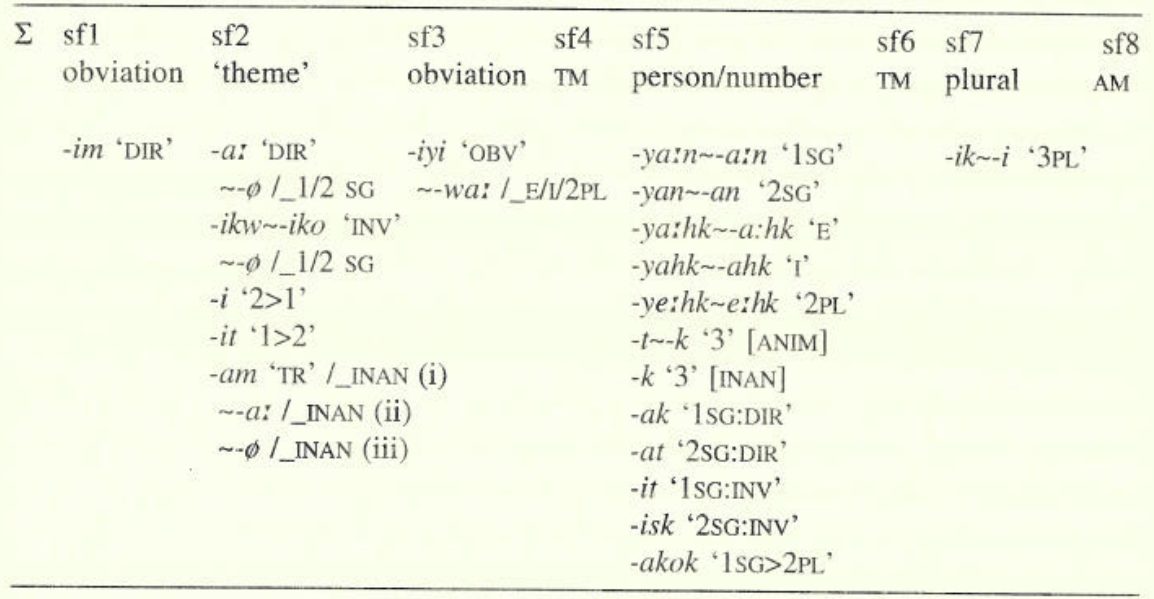

addition, a suffix slot eight for iterative aspect ('A') and subjunctive mood ('M'). On the other side there are no prefixes in the conjunct inflection. The inflectional templates in Table 6 and 7 provide the affixes for both transitives and intransitives. The only difference is that transitives have the suffix slot two activated and show some peculiarities in suffix position five, to which I shall return below. Considering the semantic features in the morphemes we detect a distinction between scenarios involving at the same time a first and a second person (so-called "local". or "I-thee / thou-me" scenarios as Hockett (1966: 65) has it) and all other scenarios.

In the "local" scenarios there is straightforward role and reference marking at work. First, there are portemanteau morphemes in suffix slot two indicating a $2>1(-i)$ and a $1>2$ (-it and -iti) relation. In the independent inflection there is no other sensitivity to role. Specifically, the choice of person and number signs in suffix five is determined by a referential hierarchy rather than by role features. First person plural exclusive ('E') has preference over second plural (which in turn outranks a third person in nonlocal scenarios, $\mathrm{cf}$. below.) In the prefix position, person marking follows the well-known $2>1>3$ hierarchy (more precisely: $2>\mathrm{E}>3$ ):

(16) a. ki-wa:pam-iti-na:n. 2-see-1>2-E (IND)

'We see you.' b. ki-wa:pam-iti-na:wa:w.

2-see-1>2-2PL (IND)

'I see youp.' 
There is a special sign (- $n$ ) used when both a first person singular and a second person singular participate. (In intransitives, the morpheme indicates first singular or second singular.)

$$
\begin{aligned}
& \text { ki-wa:pam-iti- } n \text {. } \\
& \text { 2-see-1>2-1SG } \& 2 \mathrm{SG} \text { (IND) } \\
& \text { 'I see yous.' }
\end{aligned}
$$

The picture is slightly different in the conjunct inflection. When both participants are singular, there is no portemanteau analogous to $-n$. Rather, there are two morphemes, -yan - an '2SG' and -ya:n - a:n '1SG', the choice of which is sensitive to role rather than to hierarchy. Whichever is actor, is marked in this position.
(18)
a. e:-wa:pam-i-yan.
DET-See-2>1-2SG (CONJ)
'Yous see me.'
b. e:-wa:pam-it-a:n. DET-See-1>2-1SG (CONJ) 'I see you.'

Furthermore, the conjunct inflection exhibits a special portemanteau sign for ' $1 \mathrm{SG}>2 \mathrm{PL}$ ' (-akok) in slot five:

$$
\begin{aligned}
& \text { e:-wa:pam-it-akok. } \\
& \text { DET-see-1>2-1SG }>2 \mathrm{PL} \text { (CONJ) } \\
& \text { 'I see you?.' }
\end{aligned}
$$

In non-local scenarios the semantic structure is entirely different. Here, inflectional forms do not draw semantically on role categories nor are morphemes in any way sensitive to role: "[t]he shape of the person and number affixes does not vary for subject and object. Nor are the affix positions specialized for encoding a particular grammatical function." (Dahlstrom 1986: 42, cf. Wolfart 1978). Instead, there is a so-called "theme" sign that specifies who is acting on whom with reference to the referential hierarchy in (20). The categories proximate and obviative stand for discursive empathy status so that, roughly, the proximate participant is perceived as more central in a (sequence of) situation(s). This naturally fits with the higher empathy degree (Kuno 1987) found with second and first in contrast to third persons. ${ }^{11}$

$$
2 / 1>\text { proximative }>\text { obviative }>\text { further obviative }
$$

The "direct" theme sign assigns an actor role to the person highest on (20) and indicates that the undergoer is a person lower on (20). With the "inverse" sign 
this role assignment is reversed, i.e. the highest person is undergoer, acted upon by somebody further down the hierarchy:

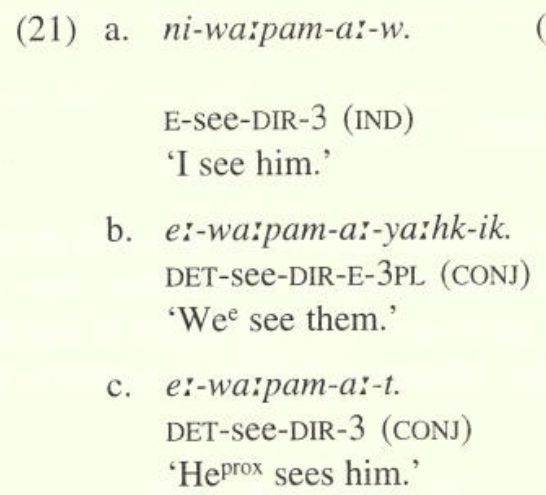

$$
\begin{aligned}
& \text { a. Iniwa:pamik/ } \\
& \text { ni-wa:pam-ikw-w. } \\
& \text { E-see-INV-3 (IND) } \\
& \text { 'He sees me.' } \\
& \text { b. e:-wa:pam-iko-ya:hk-ik. } \\
& \text { DET-see-INV-E-3PL (CONJ) } \\
& \text { 'They see use'. } \\
& \text { c. e:-wa:pam-iko-t. } \\
& \text { DET-see-INV-3 (CONJ) } \\
& \text { 'He sees himprox.' }
\end{aligned}
$$

Person marking in suffix five is determined in the same way as with local scenarios in the independent inflection, viz. by hierarchy (23a). The prefix, however, follows (23b). (A second or first person singular is marked only when the third person is inanimate, cf. Dahlstrom (1986: 58) and example (30a) below.)

(23) a. sf5: $\mathrm{E}>2 \mathrm{PL}>$ animate $>2 / 1$ SG $>$ inanimate

b. pf: $2>\mathrm{E}>3$

There are, however, some morphemes in Table 6 and 7 that might be, at first sight, good candidates for role sensitivity, and thus counter-examples to the semantic principle of inversion marking. Therefore, let me discuss these candidates in more detail.

One morpheme susceptible to role sensitivity is -im in the first suffix slot. The sign appears in direct forms only and is in complementary distribution with -iyi 'OBV' in the third slot. Dahlstrom (1986: 44) suggests that -im marks "obviative objects". This is an over-generalisation, though. The morpheme -im is not used when a third person acts on a third obviative person (cf. 21c). But it is used to indicate an obviative acted upon by a first or a second person (24a) and also to indicate a "further obviative" acted upon by a proximative (24b).

a. ni-wa:pam-im-a:-w-a E-See-DIR-DIR-3-OBV (IND) 'I see his son ${ }^{\text {obv }}$,'

$o$-kosis-a.

3POSS-son-OBV 


\section{b. wa:pam-im-e:-w-a o-kosis-iyiw-a. see-DIR-DIR-OBV (IND) 3POSS-Son-OBV-OBV 'He $\mathrm{H}^{\text {prox }}$ saw his ${ }^{\text {obv }}$ son f.obv.'}

A possessed referent is by rule more obviative than its possessor (Wolfart 1978: 257). If the possessor him or herself is obviative (as indicated in (24b) by -iyiw), the possessee is "further obviative" (marked with the regular obviative suffix $-a$, cf. op. cit. 258f). The distribution of -im in (24) compared to (21c) suggests that -im appears if and only if a direct action involves participants who are nonadjacent on (20), that is in $2 / 1>$ obviative and proximative $>$ further obviative scenarios. ( $2 / 1>$ further obviative forms do not occur.) Accordingly, we may gloss the morpheme as "strongly direct". Consequently, the distribution of -im is accounted for in terms of the referential hierarchy, rather than by role notions.

Similar arguments against a role analysis go for the suffix $-e:$ that is used in some direct forms of the independent conjugation. Judged by examples like (25) one might analyse $-e:$ as a marker for obviative undergoer:

\section{(25)}

a. wa:pam-e:-w. see-3DIR-3 (IND) 'He ${ }^{\text {prox }}$ sees him ${ }^{\text {obv }}$ ', b. wa:pam-e $-y i-w-a$. see-3DIR-OBV-3-OBV (IND) 'He $\mathrm{Hebv}^{\text {obv }}$ sees him fobv.'

However, $-e$ : does not show up when a further obviative acts upon an obviative. Such a relation is construed by inversion marking (cf. Wolfart 1978):

$$
\begin{aligned}
& \text { wa:pam-iko-yi-w-a. } \\
& \text { see-INV-OBV-3-OBV (IND) } \\
& \text { 'He } \mathrm{He}^{\text {f.obv }} \text { sees him }{ }^{\text {obv }} \text {.' }
\end{aligned}
$$

Therefore, it is only by reference to the semantic feature "direct", but not to "undergoer" or "object", that the distribution of -e: can be captured. The morpheme indicates a third person in a direct scenario.

The next candidates for role sensitivity are found in the conjunct inflection only. In suffix slot five four morphemes occur which seem to be portemanteau signs conflating role and reference features. They are, significantly, in complementary distribution with the direct and inverse signs in suffix slot two. (In Table 7, this fact is expressed by zero allomorphy with the adequate triggering context '_ $1 / 2 \mathrm{SG}$ '.) 


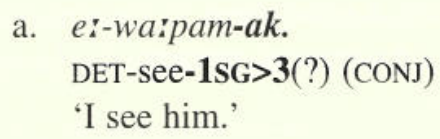

a. e:-wa:pam-ak.

DET-see-1SG $>$ 3(?) (CONJ)

'I see him.'

b. e:-wa:pam-it. DET-see-3>1SG(?) (CONJ)

'He sees me.'

On an alternative account, these morphemes are portemanteau signs that do not stand for role and reference features but that encode transitivity direction (i.e. direct vs. inverse) and reference. The sign - ak is analysed as "first person singular direct" and -it as "first person singular inverse". Evidence for this comes from the fact that the morphemes do not specify number (28) nor obviation (29) in the third person. This is done independently of role in the regular way discussed above:

$$
\text { a. e:-wa:pam-ak-ik. }
$$

DET-See-1SG:DIR-3PL (CONJ)

'I see them.'

(29) b. le:wa:pamicik/ e:-wa:pam-it-ik. DET-See-1SG:INV-3PL (CONJ) 'They see me.'

b. e:-wa:pam-iyi-isk. DET-See-OBV-2SG:INV (CONJ) ' $\mathrm{He}^{\text {obv }}$ sees you'.'

Furthermore, in one case the portemanteaux dissolve into the categories inverse and person, not into role and person. This obtains with inanimate actors (Dahlstrom 1986: 57) where the form contains the regular markers -iko 'INV' and -ya:n '1sG' (30a) instead of the -it portemanteau (30b).
a. e:-se:kih-iko-yain.
DET-Scare-INV-1SG (CONJ)
'It scares me.'
b. e:-se:kih-it. DET-scare-1SG:INV (CONJ) 'He scares me.'

Similar arguments can be adduced against a role analysis of morphemes $-e:$ and $-a m$ in the second slot of the independent inflection. The signs are restricted to verbs taking inanimate objects. The morpheme - $e^{\prime}$ occurs with first or second person actors, -am with third person actors. Taking these selectional restrictions as elements of meaning, however, would lead to wrong expectations. First, where the signs occur, there is no registration of object qualities. (This is the defining property of the so-called inanimate transitive sub-paradigm, cf. Dahlstrom 1986: 37.) Such a phenomenon is a straightforward consequence of a mere transitivity sign (whence the gloss ' $T R$ ' in the tables) which is restricted to inanimate stems. But it is difficult to 
explain if the morpheme would encode an actor role. Second, we wouldn't expect person to be marked independently if - $e$ : and -am were to carry person features:

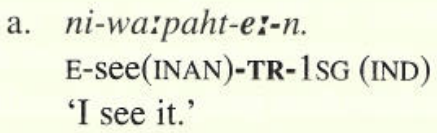
b. wa:paht-am-w-ak. see(INAN)-TR-3-3PL (IND) 'They see it.'

Furthermore, the opposition $-e:$ vs. $-a m$ is restricted to one single class of verbs, the so-called class (i) (cf. Table 6). In conjunct inflection, the opposition is neutralised in a general transitivity marker -am. Therefore, it is not a general phenomenon at all.

In sum, these arguments corroborate the hypothesis that non-local scenarios in Plains Cree are entirely built on semantic categories of direction (direct vs. inverse) and reference (person and number). There are no signs standing for the role of a referent, but rather "theme" signs that indicate that two roles are present and furthermore that specify in which transitivity relation ("direct" or "inverse") the referents stand to each other. This specification is expressed as 'descending' (direct) or 'ascending' (inverse) the referential hierarchy (20). Table 8 contrasts this with what was found in Belhare verb inflection.

The sharpest contrast between Plains Cree and Belhare lies in the semantics of inflectional morphemes for non-local scenarios. Whereas Plains Cree relies on the interplay between direction (direct vs. inverse) and reference signs, Belhare merges referential signs with role. Additionally, however, Belhare is sensitive to direction on the supramorphemic level, i.e. on the level of morpheme position and allomorphy. Comparing the internal structure of Belhare supramorphemic inversion with morphemic inversion in Plains Cree, there is still a difference in the referential hierarchies. First, Belhare makes an

Table 8. Contrasts between Belhare and Plains Cree conjugation

morphemic structure

Belhare

role and reference supramorphemic structure direction and reference (1 $>2>3$ SG $>3$ NS $)$

\section{$\begin{array}{lll}\text { Plains Cree } & \text { local: } & \text { role and reference } \\ & \text { non-local: } & \text { direction and reference }\end{array}$ \\ $\begin{array}{lll}\text { Plains Cree } & \text { local: } & \text { role and reference } \\ & \text { non-local: } & \text { direction and reference }\end{array}$ \\ $(2 / 1>$ prox $>$ obv $>$ f.obv $)$}


ordered distinction between first and second person which Plains Cree does not register. Second, third person is divided into proximative and obviative in Plains Cree, but into singular and non-singular in Belhare. It is interesting, however, that there is some indication in Plains Cree that obviation and piurality have something in common. Yet this is observed not on the morphemic level, but in polysemy structure. Obviative and plural formally converge in noun inflection where the same morpheme marks both obviative status of animates and plural of inanimates. (Obviative animates do not show number distinctions.) The same is true for verbs in the-independent conjugation. With inanimate verb stems, - $a$ (suffix slot seven) encodes a plural participant, and with animates it indicates obviation. The convergence is hardly accidental as it shows considerable diachronic stability and is reconstructed already for Proto-Algonquian (Wolfart 1973: 14; Goddard 1974: 318). This suggests that a splitting of third person singular and non-singular is perhaps far less deviant from the kind of hierarchy we might want to find in inversion, be it on the morphemic or on the supramorphemic level. In fact, there seems to be a Tibeto-Burman language (of the Rung group), the lCog-rtse dialect of rGyaron (spoken in Northwest Sichuan, Nagano 1984), ${ }^{12}$ that shows the same hierarchical arrangement of $3 \mathrm{SG}>3 \mathrm{NS}$ as in Belhare.

\subsection{The lCog-rtse rGya-rôn case}

In lCog-rtse rGya-ron, the ordered splitting of $3 \mathrm{sG}>3 \mathrm{NS}$ underlies a kind of morphemic inversion reminiscent of the Algonquian type and is, as we shall see, not a supramorphemic phenomenon of the Belhare type.

Table 9. lCog-rtse rGya-rôn transitive inflection (non-local scenarios)

\begin{tabular}{|c|c|c|c|c|c|c|c|c|}
\hline $1 \mathrm{SG}>3$ & & $\sqrt{ }$ & $-n g$ & $3>1 \mathrm{sG}$ & & $w u-$ & $\sqrt{ }$ & $-n g$ \\
\hline $1 \mathrm{DL}>3$ & & $\sqrt{ }$ & $-c h$ & $3>1 \mathrm{DL}$ & & $w u-$ & $\sqrt{ }$ & $-c h$ \\
\hline $1 \mathrm{PL}>3$ & & $\sqrt{ }$ & $-y$ & $3>1 \mathrm{PL}$ & & $w u-$ & $\sqrt{ }$ & $-y$ \\
\hline $2 \mathrm{SG}>3$ & $t 2-$ & $\sqrt{ }$ & $-n$ & $3>2 s G$ & tor & $w-$ & $\sqrt{ }$ & $-n$ \\
\hline $2 \mathrm{DL}>3$ & ta- & $\sqrt{ }$ & $-N c h$ & $3>2 \mathrm{DL}$ & $t 2-$ & $w-$ & $\sqrt{ }$ & $-N c h$ \\
\hline $2 \mathrm{PL}>3$ & $t \partial-$ & $\sqrt{ }$ & $-n y$ & $3>2 \mathrm{PL}$ & $t \partial-$ & $w-$ & $\sqrt{ }$ & $-n y$ \\
\hline $3 \mathrm{SG}>3$ & & $\sqrt{ }$ & $-w$ & $3 N S>3$ & & $w u-$ & $\sqrt{ }$ & \\
\hline
\end{tabular}


Let us for a moment skip the discussion of what Algonquianists call "local" scenarios. Then, the transitive paradigm presents itself as shown in Table 9. ( $\sqrt{ }$ stands for "root", $N$ "assimilates and is rather syllabic" (Nagano 1984: 16).)

Since DeLancey (1980: 53ff), the prefix $w u-\sim w$ - has been analysed as an inverse marker operating on hierarchy (32).

$$
1>2>3 \mathrm{SG}>3 \mathrm{NS}
$$

Unfortunately, this theory was virtually always based on diachronic and/or cognitive (conceptual) or pragmatic arguments (DeLancey 1980, 1981 and Ebert 1987, 1990). Therefore it does not come as a surprise that the analysis came under attack from a point of view that strictly commits itself to a methodological separation of synchronics from diachronics and of linguistic analysis from psychological evidence and arguments (van Driem 1992). It is imperative, therefore, that the "inversion theory" be underpinned by linguistic arguments if it is not to be abandoned.

Let me first specify more exactly the inversion theory. It says that there is a morpheme $w u$ - ( $w$ - if non-initial) which means that a person which is copresent in the form is less agentive than another person who is lower on (32). Two corollaries are tied to this.

First, person and number are marked according to (32) so that the highest participant that can be distinguished morphemically is recorded on the verb. The set of person and number markers is, by this account, the forms in Table 10. This explains all distributional facts, including the $-w$ vs. $w u$ - opposition that might cause some difficulties. 1Cog-rtse rGya-ron differentiates only two $3>3$ configurations, viz. $3 \mathrm{SG}>3$ and $3 \mathrm{NS}>3$. In $3 \mathrm{SG}>3$, third person singular is the only category that can be morphemically distinguished because there is no general third person marker. Therefore $-w$ is used. (Notice that an inversion of this, i.e. a distinct form indicating a $3>3$ sG configuration is not scheduled for

Table 10. ICog-rtse rGya-rôn person/number marking in non-local scenarios

\begin{tabular}{llll}
\hline & SG & DL & PL \\
1 & $-n g$ & $-c h$ & $-y$ \\
2 & $t \partial-\sqrt{ }-n$ & $t \partial-\sqrt{ }-N c h$ & $t \partial-\sqrt{ }-n y$ \\
3 & $-w$ & \multicolumn{2}{c}{$-\phi$} \\
\hline
\end{tabular}


by the paradigm.) With $3 \mathrm{NS}>3$ scenarios (i.e. $3 \mathrm{NS}$ acting on either $3 \mathrm{NS}$ or $3 \mathrm{SG}$ ), the only person and number combination that fits a morpheme is third person non-singular. This is expressed by zero. However, a third person non-singular cannot participate in a scenario other than an inverse one, since there is no category below it on the hierarchy (32). This triggers the use of the inverse marker $w u$-. As for $w u$ - with first and second person, the fact that number of actors is not morphemically registered follows directly from the hierarchy in (32): the inverse marker indicates only that there is an actor lower than the first or second person, reference can be either to third person singular or nonsingular.

Second, the inversion theory suggests a peculiarity of "local", as against other configurations. This is indeed what we find in the forms displayed in Table 11, which completes the transitive paradigm. The semantic structure of these forms is radically different in so far as they build on portemanteau prefixes that indicate both an actor and an undergoer. ${ }^{13}$ Furthermore, whereas person and number marking in non-local scenarios (Table 9) is not sensitive to role but to referential hierarchy, in local scenarios it is the role category of undergoer that triggers number coding. This is similar to Plains Cree local conjunct inflection insofar as sensitivity is to role. It diverges, however, in that Plains Cree registers number of actor instead of undergoer (cf. examples in (18) above).

The alternative to the inversion theory that has been recently advanced by van Driem (1992: 47-54) analyses $w u \sim w$ - as a marker of ' $3 \mathrm{~A}$ '. The apparent shortcoming of this is that it does not account for the fact that $w u-\sqrt{ }$ does not designate any third person actor but the specific configuration 3NS $>3$. Van Driem (1992: 50) remedies the difficulty by having $w u$ - $\sim w$ blocked by the suffix $-w$. To state positively the semantic value of $w u-\sim w$ - in $3 \mathrm{NS}>3$, we can furthermore build the referential hierarchy (32) into the morpheme semantics. We would then postulate a polysemous morpheme combining a third person actor with a third person non-singular actor, much in parallel with the way we proceeded in Belhare. Contexts that remove ambigu-

Table 11. lCog-rtse rGya-rôn transitive inflection (local scenarios)

\begin{tabular}{llllllll}
\hline $1>2 \mathrm{SG}$ & $t a-$ & $\sqrt{ }$ & $-n$ & $2>1 \mathrm{SG}$ & $k a w-$ & $\sqrt{ }$ & $-n g$ \\
$1>2 \mathrm{DL}$ & $t a-$ & $\sqrt{ }$ & $-N c h$ & $2>1 \mathrm{DL}$ & $k a w-$ & $\sqrt{ }$ & $-c h$ \\
$1>2 \mathrm{PL}$ & $t a-$ & $\sqrt{ }$ & $-n y$ & $2>1 \mathrm{PL}$ & $k a w-$ & $\sqrt{ }$ & $-y$ \\
\hline
\end{tabular}


ity would be $-\phi$ ' 3 ' for ' $3 \mathrm{NS}: \mathrm{A}$ ' and both $t \partial-\Sigma-n / N c h / n y$ ' $2 \mathrm{sG} / \mathrm{DL} / \mathrm{PL}$ ' and $-n g / \mathrm{ch} /$ $y$ ' $1 \mathrm{sG} / \mathrm{DL} / \mathrm{PL}$ ' for ' $3 \mathrm{~A}$ '. In the latter case, this would result in an interdependent specification. First, polysemous $w u \sim w$-would assign an undergoer role to first and second person. Second, these personal signs would, in turn, indicate that $w u \sim w$ - refers to ' $3 \mathrm{~A}$ ' and not to ' $3 \mathrm{NS}: \mathrm{A}$ '. The first rule is equivalent to the inversion rule, the second to the rule of person and number marking. Consequently, the ' $3 \mathrm{~A} / 3 \mathrm{NS}: \mathrm{A}$ ' analysis is descriptively (extensionally) equivalent to the inversion theory. There is, however, some additional evidence in favour of the inversion theory. First, in contrast to Belhare, there is no independent evidence in lCog-rtse rGya-ron that non-local scenarios build on role and reference markers. In fact, $w u$ - $\sim w$ - would be the only nonlocal sign coding role. Second, intransitives do not exhibit this morpheme. Rather, they indicate third person by zero or $k a-$ in the singular, by $k \partial-\Sigma(-N c h)$ in the dual and by $k a-\Sigma(-n y)$ in the plural, allomorphy (in brackets) being determined by conjugation class (see Table 12). Thus, whereas in Belhare the category of ' $3 \mathrm{NS}: \mathrm{A}$ ' gains plausibility due to its formal combination with ' $3 \mathrm{NS}: \mathrm{S}$ ', there are no such hints in $1 \mathrm{Cog}$-rtse rGya-ron. In contrast, the identity of non-third person markers in intransitives with both their actor and undergoer counterparts in transitives corroborates the absence of role meanings in the morphemes. In Belhare, convergence of intransitive and transitive markers without role sensitivity is highly restricted, viz. to the second person sign -gak and to the number markers of suffix slot three (-chi 'DL' and $-i$ ' $1 / 2$ PL', cf. Table 3). Finally, for 1 Cog-rtse rGya-ron the inversion theory is stronger from an explanatory point of view: the ' $3 \mathrm{~A} / 3 \mathrm{NS}$ : A' theory cannot explain why first and second person are marked irrespective of role. It can only re-state the distributional facts.

It is clear, however, that more evidence is needed to decide on the approaches proposed. Indeed, more has to be known about 1Cog-rtse rGyarôn in general. For instance, Nagano (1984: 66ff) presents a special form $k a-\sqrt{ }-y$ ' $1 \mathrm{PL}>1$ ', the sense of which is not immediately transparent. First of all,

Table 12. lCog-rtse rGya-rôn person/number marking in intransitives

\begin{tabular}{llll}
\hline & SG & DL & PL \\
1 & $(k \partial-) \sqrt{ }-n g$ & $(k \partial-) \sqrt{ }-c h$ & $(k \partial-) \sqrt{ }-y$ \\
2 & $t \partial-\sqrt{-n}$ & $t \partial-\sqrt{-N} n$ & $t \partial-\sqrt{-n y}$ \\
3 & $(k \partial-) \sqrt{ }$ & $(k \partial-) \sqrt{ }(-N c h)$ & $(k \partial-) \sqrt{ }(-n y)$ \\
\hline
\end{tabular}


however, information is needed on a special, as it were, "half-transitive" paradigm that inflects only for actor role and is used only when there is no undergoer pronoun present in the clause (Nagano 1984: 68, 75). It is identical to the direct paradigm except for $2 \mathrm{sG}>3$ ending in $-w(u)$ rather than in $-n$ and except for a third person non-singular form with prefix $w u$-. One wonders whether there are some typological parallels with the Proto-Algonquian 'objective' forms as still attested in some Eastern Algonquian languages such as Delaware (Goddard 1974). These forms are used when no noun object is present. Interestingly, they make up a distinct sub-paradigm only in configurations other than $3>2 / 1$, i.e. in all direct and a couple of inverse scenarios.

Whatever future research on lCog-rtse rGya-ron will teach us, we now clearly see what it means to say that a language builds morphemically on inversion rather than on role categories. And, the possibility of morphemic inversion built on $1>2>3 \mathrm{SG}>3 \mathrm{NS}$ corroborates the hypothesis that the precise nature of a referential hierarchy is a variable independent from the difference between morphemic and supramorphemic inversion. It is this difference that the following section is dedicated to.

\section{Towards Resonance Morphology}

To properly appreciate the distinction between supramorphemic and morphemic inversion, it is helpful to study the semiotics of morphology in a general way. In the following, I shall, therefore, evaluate the difference between supramorphemic and morphemic inversion from a semiotic point of view.

\subsection{Linguistic Gestalten}

It has been recurrently suggested that linguistic forms cannot be entirely reduced to compositional distinctive features (Bühler 1934: §18; Hockett 1987: 40ff; Lakoff 1977). Rather, forms exhibit structures similar to what psychologists since Ehrenfels (1890) have called Gestalt phenomenon (cf. Rock and Palmer 1990 for a recent survey). While Bühler (1934) and Hockett (1987) confine their discussion of Gestalt phenomena to aspects of phonic structure (intonation, accent, syllable structure etc.) and Lakoff (1977) to syntactic and lexical structure, I suspect Gestalten are also characteristic of morphological 
structure. Supramorphemic inversion and other kinds of morphotactic redundancy phenomena show three properties usually associated with Gestalten.

First, Belhare redundant morphotactics is transposable as any Gestalt is. This is to say that affix position in supramorphemic inversion remains unaltered whereas the affixes themselves vary to a certain degree. Thus, the prefix position may be filled by seven different morphemes without damaging the Gestalt of the word form. The second property relates to the difference between piece and part as worked out by Husserl (1913: 226ff). It is essential for Gestalten that they are made up of dependent parts and not of separable pieces. This is the reason why I cannot remove anything from a soap bubble without destroying it. The bubble is a prototypical (and also an often cited) Gestalt. On the other hand it is easy to remove a piece from a lump of soil. In morphology the pieces are the morphemes, the parts are the redundancy phenomena. I can exchange morphemes with others or remove them altogether. Belhare forms can be formed with either $-n a$ (33a) or $-u$ (33b), and from -na-chi one can easily remove -chi (33c vs. 33a).

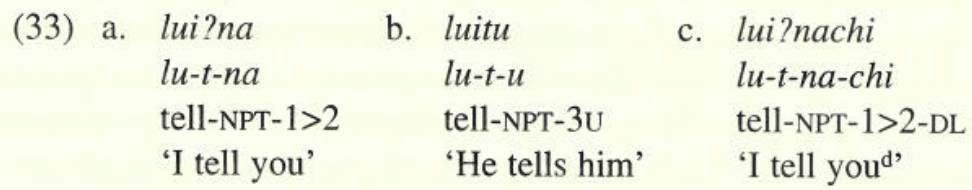

Indeed, exchangeability is a defining feature of the morpheme. In contrast, it is not possible to alter anything in affix position. The last, certainly not least Gestalt property is over-summativity or non-compositionality. Gestalten qualitatively transgress any summation of pieces and cannot be reduced to components that would exhaustively generate form and content of a Gestalt. This contrasts with morphemes for which compositionality is imperative. What is left when a morpheme has been isolated must itself be a meaningful item. This is why we hesitate to synchronically isolate -berry in cranberry although -berry appears in other contexts (e.g. blackberry). What -berry does satisfy is rime (Bolinger 1950) or, more generally, resonance (Hockett 1987), i.e. the requirement that a formal pattern be recurrent, that it appear in different contexts. This property indeed holds for Belhare supramorphemic inversion. The patterns "prefixation" and "suffixation" are recurrent, they occur not only with one single morpheme but with a whole range of morphemes (prefixation e.g. with $m a$ - ' $1 \mathrm{SG}: \mathrm{U}^{\prime}, k a-$ 'I:U', ${ }^{N_{-}}$' $3 \mathrm{NS}: \mathrm{A} / 3 \mathrm{~A}$ ', etc.). 


\subsection{Basic notions of Resonance Morphology}

It is advisable to disentangle the bunch of criteria traditionally associated with the monolithic notion of morpheme. This leads to a proper qualification of phenomena like cranberry and Belhare supramorphemic inversion as well as to working out their semiotic difference from morpheme structure.

The basic property shared by morphemes and Gestalt phenomena is, to take up a concept of Hockett (1987), resonance. In order for a form to be understood as a linguistic sign, it is imperative that the form resonate to something speaker and hearer are familiar with (op. cit. 90). There are probably, as Bybee (1985: 117f) suggests, different strengths of resonance (her "lexical strength"), depending on how frequently a form finds resonance through actual use. That there is resonance at all, however, is fundamental. "A piece is meaningful in the first instance, if it reminds the hearer of something heard before in settings that serve to define it." (Hockett, loc. cit.). Resonance is a property logically independent of the kind of function that a form serves. It is the notional top node of morphology. This is diagrammatically expressed in Table 13 where the basic notions and definitions of Resonance Morphology are summed up. The view that morphology starts from a general notion of resonance and that questions about function are subordinate (though more important) was first outlined by Sapir. He called for a morphology, termed the study of "grammatical processes" in opposition to "grammatical concepts", where "linguistic form may and should be studied as types of patterning, apart from the associated functions" (Sapir 1921: 60).

Table 13. Basic notions of Resonance Morphology

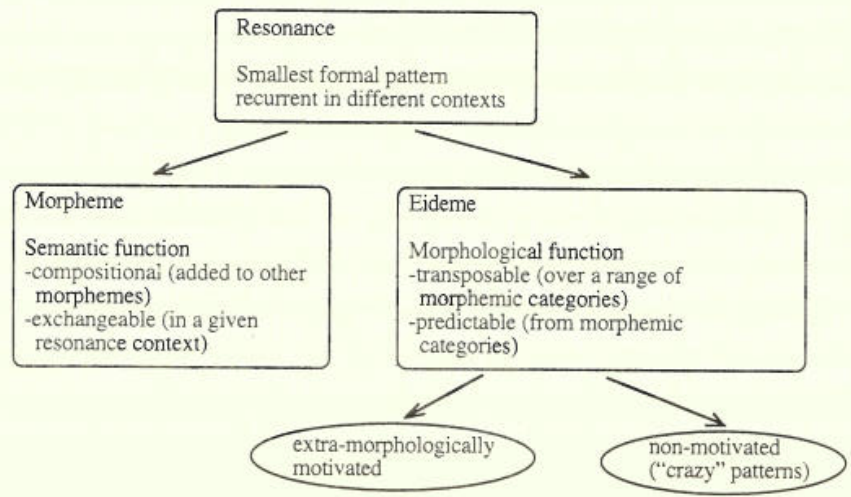


Resonance, defined by recurrence of a formal pattern, is subdivided according to the function it exposes. On one side, there are resonances with a semantic function, i.e. morphemes. On the other side, there are "secondary associations" (Hockett 1958: 297) of forms that do not bear semantic load but rather consist in resonances of a purely morphological order. These are the Gestalt phenomena that have been discussed in the preceding and whose properties will be further explored in the following. For the sake of terminological convenience, I venture to call them "eidemes" (cf. note 18 for an etymology). It seems that this subdivision of resonance into morpheme and eideme was somehow felt in the Prague school "projet de terminologie phonologique standardisée" but, unfortunately, not further explored nor terminologically established. ${ }^{14}$ Therefore, the morpheme is defined twice (Projet..., p. 321), once as a resonance that may well be a pure eideme ("unité morphologique nonsusceptible d'être divisée en unités morphologiques plus petites") and, connected by "c'est-à-dire", as a resonance which probably must be a "real" semantic morpheme ("une partie de mot qui, dans toute une série de mots, se présente avec la même fonction formelle et qui n'est pas susceptible d'être divisée en parties plus petites possédant cette qualité"). Closer to a separate notion of "eideme" was Whorf when he asserts that "we also have word groups which are configuratively distinct and yet have no difference in meaning; these we may call isosemantic or purely formal classes." (1945 [1956: 99], original italics). Equally close to the distinction of morpheme and eideme was Bolinger (1948). He proposed to define the morpheme as a minimal active, i.e. compositional and productive form. Opposed to this are what he called "components", which are "locked in 'inert bondage"" (1948: 22; also cf. Plank 1981: 196). This view, however, precludes that eidemes can be productive or that they can innovatively arise in language history. It is an advantage not to prejudge these options. In the next section, I shall indeed postulate productive eidemes in derivational morphology. A case of innovated eidemes will be demonstrated in section five.

By "formal pattern" I envisage not only phonological structure but also positional patterns. We have already seen this working in the eidemic domain, viz. in Belhare morphotactic inversion. However, position can of course also be exploited for semantic function. Especially within the domain of the word, affixes may be distinguished by position alone. An example from Belhare is -chi in suffix slot three meaning 'dual (intransitive subject, actor or undergoer)' and in suffix slot six meaning 'non-singular actor or undergoer.' The 
difference is evidenced by contrasts such as (34), where in (34a) -chi precedes $-u$ but in (34b) it follows $-u$.

(34)

a. luichuga.
lu- $t$-chi-u-ga
tell-NPT-DL-3U-2
'You' tell him.'

b. luituchiga. lu- $t$ - $u$-chi-ga tell-NPT-3U-NS:U-2

'You' tell them.'

Here, phonological structure is eidemic while it is up to position to realize the morphemes. Evidently, there is no co-variation to be expected between position patterns and eidemes or between sound patterns and morphemes.

Before I approach the notions "morphological function" and "motivation", which are of greatest concern for supramorphemic inversion, I shall give some hints on the implications of Resonance Morphology to show the advantages and plausibilities of the theory and its concept of eideme. ${ }^{15}$

Resonance Morphology overcomes the controversy on where to stop slicing words and allows a more realistic view on form-meaning relations beyond the one-to-one ideal.

First, the debate between rule maximalists who are eager to slice word forms into morphemes to the degree of mere absurdity and rule minimalists who hesitate to cut any form (cf. Plank 1981: ch. 4), becomes insignificant. The dilemma presents itself most flagrantly in the often discussed phenomena of systematic resonance that cannot be handled within the framework of morpheme analysis:
a. north - south, east - west
b. father - mother - brother, sister - daughter

In all the groups, there is a sound sequence reflecting membership in a particular set of nouns. The standard criterion of compositionality prohibits setting up morphemes like -th, -st, -ther and -ter. Yet, on the other hand, we may want to capture the obvious fact that the formal relation between the noun classes is more than accidental. The very same dilemma occurs again and again in inflectional morphology. For instance, Belhare ma?i- 'E:U' and - $\eta a$ ' $\mathrm{E}: \mathrm{S} / \mathrm{A}$ ' are not by accident formally similar to $m a-\sim m a i-$ ' $1 \mathrm{SG}: \mathrm{U}$ ' and $-\eta$ '1SG:A', respectively. The shortening of ma?i- to ma- $\sim$ mai- and of $-\eta a$ to $-\eta$ reflects the number shortening from exclusive (which is [+speaker -addressee]) to first singular (which is [+speaker] only). The very same relation obtains morphemically in intransitive inflection where the so-called 
first person singular is expressed as singular of exclusive (cf. Section two). It is, within morpheme analysis, not possible to divide ma? $i$ - into $m a$ - and - $? i$ - or $-\eta a$ into $-\eta$ and $-a$, as neither $-2 i$ - nor $-a$ is a recurrent pattern with consistent meaning, i.e. not a morpheme. The components attach only to $m a-$ or $-\eta$ itself, respectively. On the other hand, we would miss the systematicity in content relations, if we did not cut the morphemes. In this dilemma, the notion of paronymy offers a third way. We do not have to slice and nevertheless we can account for systematic relations. The common pattern found in paronymic

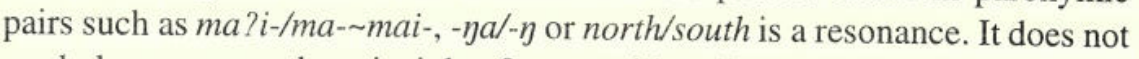
work, however, on the principle of compositionality (as a morpheme would). Rather, the resemblance monitors a word "as a whole," as Bolinger (1950: 127) aptly noted (in a similar vein, Plank 1981: 191). Moreover, the patterns under consideration are lexically predictable and transposable over two morphemes each. Therefore, they belong with the eidemic resonances in Table 13.

Second, Resonance Morphology does not, in contrast to classical morphemics, impose an a priori preference for one-to-one relations between form and meaning. One-to-many relations, i.e. polysemy (used in the strict sense from section two), is a natural phenomenon in Resonance Morphology. The complete formal convergence of semantically distinct morphemes is the extreme of paronymy (cf. note 6). Morphemes that are distinct on clear linguistic grounds are not only partially but completely resonant to each other. This fact, i.e. the resonance in formal structure is predictable from the meaning of the morpheme. It does not therefore affect semantic structure by creating a new Gesamtbedeutung. Disregarding the subordinate issue of motivatedness, ${ }^{16}$ Resonance Morphology can adequately treat all kinds of polysemy as eidemic phenomena. In contrast, traditional morpheme analysis is more concerned with eliminating polysemy. Its focus is, as we have seen in section two, more to discern and to define the smallest (non-resolvable) semantic units, rather than to account for the relation between these units in polysemous morphemes. The same traditional neglect can be observed in the other deviation from the one-to-one ideal: allomorphy (i.e. one-to-many relations). When an allomorph is triggered by more than one morpheme environment, these environments define an eidemic class in a way similar to morphotactically defined classes. This is the case with negation allomorphy in Belhare. According to rule (14), the prefix part of ${ }^{N_{-}} \Sigma-n(i)$ 'NEG' is not realized in inverse scenarios higher than $3>3$ scenarios. Another example is 
the morpheme for first person singular undergoer, ma-. It has an allomorph in $k a$ - triggered both by the imperative sign $a$ - $\sim a n$ - and by a co-occurring second person morpheme $(-g a k \sim-k \sim-g a)$. The environments of this rule make up a well-motivated class: they are both characterized by an appeal to the addressee in a strictly "local" ("I-thee") context (cf. the Algonquian pattern in Section three; also cf. Silverstein 1976 and Heath 1991).

Both the descriptive need of defining a combined triggering environment and the motivation behind this combination show that allomorphy is not necessarily a mere "deviation" from a "regular" kind of form-meaning relations. Moreover, it can be grounded in a general and systematic manner. This is the case with both our examples. Negation allomorphy is motivated by the same concept of inversion that is also relevant to morphotactics. First person singular undergoer allomorphy is grounded in the same notion of "local context" that also motivates a convergence eideme, viz. the polysemy of $k a$ as an allomorph of $m a$ - '1SG:U' and as a sign for 'I:U'. Both signs occur when both speaker and addressee are involved, either in a $2>1$ scenario or in a $3>1 \& 2$ (' $3>I$ ') scenario. Notice that it is not possible to assign $k a$ - a unitary meaning like "local context" or "you and me". In co-occurrence with -gak ('2'), $k a$ - cannot refer to an inclusive undergoer. In this environment, the prefix agrees with $\eta k a$ 'I' only (36a), agreement with $\eta k e c h i$ 'we ${ }^{\mathrm{di}}$ ' (or $\eta k e$ 'we $\mathrm{p}^{\mathrm{p}}$ ') is ungrammatical (36b).

(36) a. jkacha cama kathukpiuka $i$ ?

${ }^{N}$ ka-cha cama ka-thuk-pi-t-ga i

1SG-ADD food 1SG:U-cook-BEN-NPT-2 Q

'Do you cook for me, too?'

b. * ykechi cama kathukpiuka i?

${ }^{N}$ ke-chi cama ka-thuk-pi-t-ga $i$

1NS-DL food 1sG:U-cook-BEN-NPT-2 Q

'Do you cook for usi?'

As an effect, the meaning 'Do you cook for (both of) usi?', which is conceptually available for the bilingual Belhare speaker through Nepali (37), cannot be conveyed by a single form like (36b) but only indirectly by (36a). 
These facts can only be accounted for if $\mathrm{ka}$ - in the context of a second person (actor) is analysed as an allomorph for '1SG:U' and not as a general morpheme for "local contexts". On the eidemic level, though, $k a$ - '1SG:U' and $k a-$ 'I:U' are systematically related and this relation is well motivated by the pragmatic category "local context" or "speech act participants".

Portemanteau morphemes are yet another phenomenon that is natural in Resonance morphology but deviant in traditional 'one-to-one' morphology. The portemanteau quality of $-n a$ ' $1>2$ ' is an eideme transposed over the two morphemic (semantic) categories "first person actor" and "second person undergoer" (cf. Section two). However, in contrast to the previously discussed eidemes, the transposition obtains here on the syntagmatic rather than on the paradigmatic axis of morphology. In -na the two related categories are co-present in a single event ("first person acting on second person") while an eideme such as the polysemy structure of $k a$ - encompasses paradigmatic oppositions (first person singular vs. first person inclusive). The fact that the scenario $1>2$ is expressed by a portemanteau rather than by a morpheme sequence, does not add information. It is, like any other eideme, entirely predictable from the morphemic categories involved. The -na portemanteau is motivated: it recapitulates the notion of "local" context found above in allomorphy and polysemy morphemes. This corroborates once more the systematicity of the phenomenon.

The systematic nature of motivations for paronymy, polysemy, allomorphy and portemanteau effects suggests that it is an advantage for a morphological theory not to prejudge their naturalness and diffusion (cf. Bybee 1985). We should, as Hockett (1987: 82f) has insistently warned us, be cautious not to commit what he calls the "Great Agglutinative Fraud". Indeed, even in diachronic development, where there often seems to be a drive towards one-to-one relations between form and meaning, this drive is by no means an all-pervasive stampede or even a "law" (cf. Anttila 1989: 100, Heath 1991: 80).

\subsection{Morphological function, semantics and motivation}

It is a strange irony of descriptive morphology that its aim is traditionally restricted to uncover the semantic structure of morphemes. Resonances of a purely morphological (!) kind are hardly ever a focus of systematic interest. This may be due to the difficulty of appreciating the function tied to eidemes. 
In Table 13 above I have stipulated a "morphological function". Thereby I primarily intend the kind of function that has been discussed by Wurzel (1989), viz. a function that organises the lexicon by bringing forms into paradigms, and I may add, into lexical fields as in example (35) above (also cf. Bybee 1985: ch. 3). An illustration of paradigm-organizing function is easy to see with case allomorphy in Indo-European languages. In Latin, for example, exactly two case forms define the inflection of a given noun and determine, thereby, its membership in the declension class system. Thus, from cāsus, cāsūs ('case', us-class) as against modus, modì ('mode', o-class) or genus, generis ('gender', consonantal class) and also as against cornu, cornūs ('horn', $u$-class) we can infer all other case allomorphs of the word. Moreover, the lexicon is compartmentalised into classes. It might be that both implicational paradigm structure and lexical classification counter-balance morphological complexity and, thus, increase the learnability and handiness of the language.

Without a notion of eideme, morphological function must be tied to the morpheme. This has the disadvantage of loosening the definitional criteria of the morpheme. Consequently, Wurzel (1989: 28f) has to count markers of inflectional classes showing up in case allomorphs, as morphemes. The problematic out-come of such a position is that syntax would then require additional "macro-morphemes" like "genitive" to operate on case. Nearly fifty years earlier Whorf (1945 [1956: 99]) put declension classes under the title of "isosemantic or purely formal classes", a notion that is, as noted in the preceding section, similar to "eideme".

Another function that presumably derives from "morphological function" is for predictable stem forms and other morphophonological effects to serve as "co-signals" (Dressler 1985: 334 et passim). Most suggestively, Andersen (1980: 31f) speaks of "useful cues...in decoding messages" in that they "point to the signantia or signata of grammatical morphemes". ${ }^{17}$ Whether this is a psycholinguistically sound interpretation of morphological function is open to investigation. For linguistic purposes, it suffices to deal with eidemic patterns as an aspect of language structure that is important as such, especially in those cases, where it is descriptively needed in order to formulate a regularity and in those cases where an eideme appears to be motivated rather than to be an accidental assemblage of forms.

What is semiotically of more impact than the precise nature of morphological function, is its difference from semantic function. It is particularly 
here that the notion of eideme provides perspectives not available from traditional theories.

Contrasting eidemic with morphemic inversion, we detect that the former does not affect semantics but only formal structure. Morphemic inversion, on the other hand, does crucially engender a specific semantic make-up of verb forms. ${ }^{18}$ It may be of help to introduce a metaphor that the language philosopher Anton Marty applied to phenomena with similar characteristics as eidemes. He summarizes: “...hier handelt es sich um etwas, was zur Ausdrucksmethode gehörig, eine Vorstufe und gleichsam Vorhalle des Verständnisses und nicht dieses selbst ist..." (Marty 1908: 149). Eidemic inversion operates in "the vestibule" of meaning, whereas morphemic inversion operates in the semantic structure itself.

Phenomena that do not exhibit a semantic function may still be motivated. This means that the set of morphemic categories over which an eideme is transposable exhibits some coherence that can be shown to be grounded in an extra-morphological domain, ${ }^{19}$ such as a phonological or, presumably most prominently, an interactional (pragmatic) or generally cognitive domain. An example for phonological motivation is the so-called third or consonantal declension class in Latin. The stems of its members are characterized by the property of ending in a consonant. Pragmatic motivation is at work in the range of eidemes in Belhare (allomorphy, polysemy, and portemanteau) that prevail in "local" contexts, where both speaker and addressee participate. Also the motivation of eidemic inversion (morphotactics and allomorphy) resides in a pragmatic domain in so far as the crucial notion of empathy directly derives from the communicative category of person (cf. Silverstein 1976: 117). Cognitive in a more general sense is the motivation of the paronymic eidemes in (35), which collocate cardinal directions (35a) or kinship relations (35b). In the following, we shall see that also syntactic phenomena and even semantic structures can provide motivations for eidemes. This will further illuminate the distinction between motivation and semantics.

Consider Latin declension classes other than the consonantal class. These classes partly divide the lexicon along the guidelines of a syntactic agreement property, viz. gender. It is typical, however, that there are always clear counter-examples. The us/i-class, for example, contains masculines (e.g. modus) and feminine town, island and tree names (e.g. Corinthus, Peloponnēsus or mālus, respectively). There are, however, also a few neuters 
like vulgus 'people' or virus 'poison'. This shows the difference between the motivation of an eideme and the semantics of a morpheme. For a semantic category it is crucial to be coherent. A semantics (enhanced by pragmatic inference rules) from which not all intended tokens can be derived, is just wrongly construed. This can be illustrated by gender as a morphemic category, i.e. bearing a semantic function. An example is English prefixed pronouns as in he-goat vs. she-goat. We do not expect to come across a masculine she+noun form. If we do, the semantic analysis of she-needs revision. For a motivated category, in contrast, coherence may be partial, i.e. bound to a motivational domain rather than pervading all and only the instances of the category. Furthermore, different domains can be relevant, as indeed is the case in our Latin example. Still, we have to reckon with the possibility of non-motivated eidemes. For instance, within the German nonfeminines we find an array of declension classes that do not (at least synchronically) exhibit any transparent extra-morphological motivation. Compare, e.g. class VII Mann, Land, etc. with class XII Dorn, Auge, etc. (Carstair's (1987: 235ff) numbering). Such eidemes are glossed "crazy patterns" in Table 13. My present focus of interest lies in motivated eidemes, though. The contrast between Latin declension classes and English prefixed pronouns shows that similar domains may be motivations in one language but act as semantic (morphemic) categories in another. ${ }^{20}$ The same phenomenon shows up in comparing Belhare to Plains Cree or 1Cog-rtse rGya-ron. A pragmatic domain of inversion motivates in Belhare an eideme but is part of morpheme semantics in Plains Cree and $1 \mathrm{Cog}$-rtse rGya-ron. Such a relation between eideme and morpheme may be found even within the borders of a single language. In the preceding section I contended that the eidemic paronymy in Belhare ma?i- 'E:U' / ma- mai- '1SG:U' and - $\eta a$ 'E:S/A' / - $\eta$ '1SG:A' is motivated by a systematic relation between exclusive and first singular. This relation is present as a morphemic structure in the same language. It occurs, as we have seen, in another subdomain of inflection: in intransitive conjugation. More instances of this kind of co-existence will be observed in Section six.

Whereas semantics determines the distribution of a sign, motivation is by definition non-determinative. It is nothing more than an external category from which a motivated category becomes plausible. The semiotic rationale behind this is that motivation is a relation that emerges only after the formal and functional structure of an eideme has been established. It is not, however, 
an interpretation post festum as it were. Rather, motivation consists in the activation of an extra-morphological domain that is linguistically or cognitively available in a given speech community. In the example of the Latin third declension class this was a phonological domain. In our second Latin example it was a syntactic domain of agreement and reference tracking that operates on gender. (This syntactic phenomenon is in turn motivated by nonlinguistic dimensions, the most apparent one being sex. ${ }^{21}$ ) In the example of Belhare "inverse" and "local context" eidemes, the domain was pragmatic. Finally, in the Belhare paronymy eideme with first person markers, the domain was semantic. Motivation does, as Merleau-Ponty (1945) has it, "validate" such a domain: "Ainsi un deuil motive mon voyage parce qu'il est une situation où ma présence est requise, soit pour réconforter une famille affligée, soit pour rendre au mort les "derniers devoirs", et, en décidant de faire ce voyage, je valide ce motif qui se propose et j'assume cette situation. La relation du motivant et du motivé est donc réciproque." (p. 299f; second italics added) and "Le prétendu motif ne pèse pas sur ma décision, c'est au contraire ma décision qui lui prête sa force.” (p. 497) The reciprocal nature of motivation reveals its function and raison d'être. It serves to ease the manipulation of a formal pattern by linking it to other domains.

With regard to the kind of pattern exemplified by north - south, east west, it has often been remarked that there might be considerable idiolectal variation in 'recognizing the similarity' (cf., e.g. Hockett 1987). It does not follow from this, however, that the difference between a morpheme and an eideme (a paronym in this example) is a matter of degree. What varies is not the quality and function of the resonance but rather, if it is an eideme, the consistency of its motivation or the "degree of lexical connection" (Bybee 1985: 118) between the morphemes that the eideme collocates. This is a straightforward corollary from the semiotic status of motivation as against semantics. The value of motivation does not reside in creating and confining a message to be transferred. The content of a message that is linguistically encoded (and not pragmatically inferred) is its semantic structure. This part of the linguistic sign requires a neat agreement between hearer and speaker in order for a communicative act to be successful. In contrast, motivational structure has no function in the communicative act; it does not have to be completely shared by speaker and hearer. It is rather when we learn and "operate" a morphological system where motivational structure unfolds its function. Semantics is what gives language its force to manipulate thought, 
action, and speech; motivation is what, in turn, reflects thought, action, and speech.

The distinction between the semantic morpheme and the (potentially) motivated eideme entails a theory of derivational morphology based on the traditional concept of analogy. This view as purported in an elaborate way by Plank (1981) distinguishes analytical and synthetical relevance of a given resonance. This ultimately yields a dissociation of the factor of productivity (synthetical relevance) from the morphological status of a given resonance (i.e. whether it is analytically relevant as a morpheme or as an eideme). Both a morpheme and an eideme can be equally productive in the coinage of new lexical items. Productive morphemes require rule-based composition, productive eidemes work by means of analogy. In derivation, the former is probably less common than the latter (cf. Derwing and Skousen 1989). By closer inspection, most of rule-based derivation turns out to be analogy: "We usually think of a suffix as an independent linguistic element which may be mechanically added to other words or stems. Tennis players have introduced the noun server, which seems to consist of the verb serve plus the suffix -er. This simple and obvious explanation of derivatives is the one implied by all our grammatical terminology. The fallacy in it is the assumption that a suffix is separable from the stem, in other words, that -er itself indicates the agent. The problem in the minds of those who originated the noun server was not, 'What shall we add to the verb serve to name the man who serves?' but, 'What is the word that stands to serve as player stands to play?'” (E. H. Sturtevant quoted by Plank (1981: 64)) The tacit though correct assumption behind Sturtevant's approach is that $-e r$, i.e. /-ə[I]/, is not a compositional morpheme but rather an eideme, which is by definition not isolatable. This is borne out by words like butcher and author, which belong with server as much as baker or burglar. Taken all instances of words in /-ə[.I]/ together, the eideme will probably show considerable variation in 'degrees of lexical connection', as the theory of motivation would suggest. Such effects cannot be accounted for as long as semantics and motivation are not strictly separated.

The concept of motivation gives a richer handle not only on declension classes or derivational morphology but also on supramorphemic inversion in Belhare. In the following section, I shall further explore the motivation that underlies inversion in Belhare. 


\subsection{Motivation of morphotactic eidemes in Belhare}

When presenting the Belhare morphotactic eideme, I discussed only one range of elements in the prefixation class, all motivated by empathy. From what has been said in the preceding section, we may expect now that there are other elements in the same eideme, elements that are motivated by other domains. In fact, along with the role and reference markers used in inverse scenarios, prefixation also occurs with optative forms, third person nonsingular intransitive subjects and negation. The association of inversion with third non-singular intransitives and negation is a recurrent pattern in Kiranti languages (Ebert 1991: 84f). This makes it the more imperative to explore the general motivation that is responsible for the phenomenon. The best cue to this, however, is provided by the complex semantics of the optative prefix.

The optative morpheme $a k$-indicates that the subject (i.e. the $\mathrm{s}$ or A referent) does not control the event depicted by the verb and that the speaker wants an intermediary to control in lieu of the subject. In translation, this means that the speaker agrees (or disagrees) to someone's undertakings $(38 \mathrm{a}, \mathrm{b})$, suggests an action (38c) or wants to cause somebody to perform an action (38d).

(38) a. na pucha ak-ta, ak-yuך.

DEM snake OPT-come OPT-be

'Let this snake come, it's OK when it's there.' [it is a deity]

b. ankhatni.

$a k-^{N}-k h a t-n i$

c. akguyjandu.

OPT-[-go-NEG]

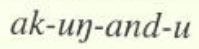

'He may not go.' 'She should take it [the tablet] with water.'

d. anthukgai!

$a k-{ }^{N}-$ thuk-ai

OPT-3NS:S-cook-EXCL

'They should cook!' [go and tell them!]

The intermediary who is entitled to care for the speaker's wish, is the addressee of the current speech act. It can also be an impersonal instance as in (39). 
(39)

wet ak-ta.

rain OPT-rain

'I hope it rains.' [said when there is no rain]

or: 'It may rain, that's OK.' [said when it is raining]

Expressions like (40) are common while worshipping.
a. aknuna.
ak-nu-na
OPT-cure-E
'I wish to be cured.'
b. dukhi aycaniy. dukhi ak- ${ }^{N}-$ ca-ni-na problem OPT-[-eat-NEG]-E 'I wish not to have problems.'

A paraphrase of (40a) would be a causative imperative like nu ka-mett-a (cure 1SG:U-CAUS-IMP) 'Make me healthy!' where the addressee is made explicit. The following example is from a story where the Death asks Viṣu for a blessing.

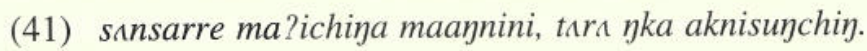
ina burdan kapira! sınsar-e ma?i-chi-na ma-ak- ${ }^{N}-n i-n i \quad$ tıra $\eta k a$ world-LOC human-NS-ERG 1SG:U-OPT-3NS:A-See-NEG but 1SG ak-nis-u-chi- $\eta \quad i-n a$ bardan ka-pir-a OPT-see-3U-NS:U-1SG:A DIST-DEM blessing 1SG:U-give-IMP 'People may not see me in the world, but I may see them. Give me this blessing.'

First person optatives, where the speaker is simultaneously the subject of the verb, are restricted to situations where the subject is deprived of control on lexical (40) or pragmatic (cultural) grounds (41). The optative marker semantically indicates this status of the subject. It does not suggest an active concession of control. Therefore, $a k$ - cannot be used to concede intentionally one's own controller status to an intermediary: (42) cannot be used to express a desire for water but only as the report of an invented optative speech act.

$$
\begin{aligned}
& \text { akguпuך. } \\
& a k-u \eta-u-\eta \\
& \text { OPT-drink-3U-1sG:A } \\
& \text { 'I assume that s/he would agree with my drinking.' } \\
& \text { (not: 'I'd like to drink.') }
\end{aligned}
$$


This communicative status is usually made explicit. In (43a), the particle -no indicates that the speaker came to a conclusion on his own; it is thus often slightly adversative. Similar in function are the narrative report particle used in (43b) and the irrealis mood marker suffixed in (43c).

(43) a. akguyumno, icha nliu?ni.

$$
\begin{aligned}
& a k-u \eta-u-\eta-n o \quad i \text {-cha } n \text {-li-t-ni} \\
& \text { OPT-drink-3U-1SG:A-CONF one-ADD [-become-NPT-NEG] } \\
& \text { 'I guess I may drink it, it won'tharm.' }
\end{aligned}
$$

b. aylunanbu.

$a k^{N}-l u-n a-n i-b u$

OPT-[-tell-1>2-NEG]-NARR

'I shouldn't tell you, they said.' c. ayluatnanbe. $a k^{N}-l u-a t t-n a-n i-b e$ OPT-[-tell-PT-1>2-NEG]-IRR

Whereas an unmarked first person optative like (42) cannot be used in a direct optative act, it can be used to manipulate the "footing" (Goffman 1979), i.e. the complex setting of speech act participation. For (42) could be used to mean 'I assume that somebody would agree with my drinking'. Thereby the speaker projects an invented optative speech act and tacitly introduces a third person responsible for the utterance. Sentence (44) was said in a meeting where people discussed whether some donated money should be equally shared by the members of all "god(ancestor)-houses" or whether it should be distributed according to the social importance of particular "god-houses". Fearing that on the second proposal some "god-houses" would not get money at all, one of the discussants says (44).

$$
\begin{aligned}
& \text { sıp may khim-chi-a ak-chitt- } u \text { - } m \text {. } \\
& \text { all deity house-NS-INSTR OPT-find-3U-1PL:A } \\
& \text { 'We may get [money] through all god-houses.' }
\end{aligned}
$$

By using the optative, however, he tries to sell his opinion as somebody else's, viz. the donor's opinion. The trick works under the (correct) assumption that the speaker's and the donor's opinion agree. However, because the donor officially declared that he will not take any public stance in the issue the speaker cannot add a report particle (e.g. - $b u$ 'NARR') without getting into conflict with the donor, who is also present in the meeting. Thus, (44) introduces the donor as a relevant authority without forcing him to become a participant in the decision process. A more explicit translation of (44) would be 'I assume that the donor wants us to get money through all god-houses'. 
the form shows a constant mismatch between morphemically encoded reference and immediate illocutionary reference. It is thus marked as deviant from a regular one-to-one correspondence between reference and illocutionary structure.

This suggests that prefixation in Belhare is more generally motivated by mismatches of morphemic reference and another domain, here pragmatic structure. This is in parallel with supramorphemic inversion. Also here, it is the pragmatic dimension where a mismatch phenomenon occurs. Instead of illocutionary structure, though, it is the empathy driven viewpoint that is relevant: direct and unmarked are those scenarios where the referentially prominent participant (in Belhare the actor) coincides with a viewpoint close to the speaker's own viewpoint. Inverse and prefixed are those scenarios where the two kinds of prominence diverge, i.e. where there is a mismatch between reference and empathy.

The same sensitivity to mismatch between reference and empathy is responsible for prefixation of third person non-singular intransitive subjects. The morpheme indicating this scenario $\left({ }^{N_{-}} \sim m i-\sim \eta \mathrm{m}^{-}\right)$is formally identical with the exponent for third person non-singular in actor role. This convergence itself is motivated by third person non-singular being the lowest category on the Belhare referential hierarchy $(1>2>3 \mathrm{SG}>3 \mathrm{NS})$. An actor with this reference is a starting point that deviates most from the empathy driven viewpoint. It is, therefore, twice marked, as inverse and, within this, as "extreme inverse". To have it coded in the fashion of an $\{\mathrm{S}, \mathrm{A}\}$-subject category is a straightforward reflex of referential markedness in a language like Belhare, whose syntax relates referential prominence to a $\{\mathrm{S}, \mathrm{A}\}$ rather than to a $\{\mathrm{s}, \mathrm{U}\}$-pivot (cf. Section two).

Notice that this is not a mere "split accusativity" effect that opposes an inflectional $\{\mathrm{S}, \mathrm{A}\}$ category for third person to a $\{\mathrm{S}, \mathrm{U}\}$ category for first and second person. Such a view is not only at odds with the split ergativity pattern in case marking, where roles are grouped in the opposite way (viz. $\{\mathrm{S}, \mathrm{A}\}$ for first person singular vs. $\{\mathrm{s}, \mathrm{U}\}$ for all other persons, cf. Section two). The view is problematic even if we confine ourselves to verb morphology. Whereas it is true that third person consistently distinguishes a $\{\mathrm{S}, \mathrm{A}\}$ category $(-\phi$ if singular, ${ }^{N_{-}} \sim m i-\sim \eta$ - if non-singular) and an undergoer category ( $-u$ ' $3 \mathrm{U}$ '), this also holds for a rather different participant configuration. With first person nonsingular reference, the morpheme $-\eta a^{\prime}$ ' $E$ ' for exclusive and $-\phi$ for inclusive collapse $\mathrm{S}$ and A whereas -ma?i 'E:U' and $k a$ - 'I:U' single out undergoers. On 
the other hand, neither second person nor first person singular follows such a pattern. The second person marker (-gak -k -gak) is not specified for role at all, and first person singular has a specialized marker if it is in actor role $(-\eta)$. Even more problematic for a split-accusativity theory is that Belhare person marking is governed by what Silverstein (1976) has termed "global" rules. Such rules are different from simple collocation rules that underlie the notion of accusativity ("treat $S$ and A alike but U differently"). Global rules are context-sensitive. Take, for instance, one of the number marking rules formulated in section two: "With exclusive undergoers, third person actors mark dual in opposition to undifferentiated singular/plural" (rule (5a)). The person marking rules are equally sensitive to which person co-occurs in the verb form: first person singular is expressed by -na if acting on a second person, by $-\eta$ if acting on a third person, by $m a ? i$ - if it is an undergoer and by $-\eta a$ in intransitive scenarios. The second person is realized as -na if acted upon by a first person but as $-g a k(\sim-k \sim-g a)$ in all other scenarios. The accusative style marker $N_{-}(\sim \eta-\sim m i-)$ ' $3 \mathrm{NS}: \mathrm{S} / \mathrm{A}^{\prime}$ ' only applies to intransitive and $3>1$ and $3>3$ scenarios. If acting on a second person, the third person is realized by the active style morpheme ${ }^{N_{-}}$' $3 \mathrm{~A}^{\prime}$ '. The phonological link of the two morphemes, though, is one of the ultimate reasons why the inversion eideme in Belhare is thoroughly systematic.

We have seen that prefixation is motivated by a mismatch of reference structure either with illocution or with empathy. The negation prefix adds yet another domain to such a principle of mismatch or referential markedness. Except for inverse scenarios higher than third person singular (cf. rule (14) above), Belhare negates by means of the circumfix ${ }^{N}-\Sigma-n(i)$ (or by means of prefixed $m i^{N}$ - in infinitives):

$$
\begin{aligned}
& \text { nkhai?ni. } \\
& N_{-} \text {-khat-t-ni } \\
& \text { [-go-NPT-NEG] } \\
& \text { 's/he doesn't go.' }
\end{aligned}
$$

This rule has the effect that a negative scenario becomes marked and receives a prefix just in those cases where it is not yet a marked structure because of inversion. Negation marks a dissociation or intended mismatch between verbal predicate and reference, i.e. the non-application of a predicate to a referent. This recapitulates the motivation of prefixation discussed before: reference inflection does not match another dimension, here predicate seman- 
tics. This could be independently motivated by an interaction effect between linguistic and non-linguistic action. Ertel and Bloemer (1975) have experimentally shown that (at least in German) negative sentences are better recalled when paired with dissociative rather than with associative manual actions whereas affirmative sentences score better when accompanied by associative rather than by dissociative actions.

As a whole, then, prefixation is motivated by a general principle of referential markedness: a verb form belongs to the prefixation class if its reference structure does not match the structure of another domain, viz. the domain of empathy, of illocution or of predication. This principle links three fundamental domains of speech to a purely morphological, to an eidemic class.

\section{A typological parallel: French}

The two-way distinction between morphemic and eidemic resonances leads us to expect other eidemes to be motivated by the marked status of inverse scenarios, especially eidemes of paronymy or phonological morpheme structure. In other words, eidemic inversion is not only to be found in supra-morphemic patterns but also in sub-morphemic structures. This expectation is empirically fulfilled by a typological parallel found in French.

In French, as in most European languages, both phrasal and clausal initial positions tend to be linked with discourse prominence. Well-known examples of this are the politeness effect of placing second person pronouns before first person pronouns as in toi et moi instead of the crude moi et toi. In clause structure emphatic pronouns are usually in initial position. This holds true also for the focused constituent in the mise en relief-construction:

(48) a. Lui, il n'en sait rien.

b. C'est lui qui n'en sait rien.

This category of prominence is also present in some aspects of proclitic ordering with verbs. Whereas subject, direct object and the two oblique proclitics appear in a fixed order, there is variation when indirect objects are involved. (Incidentally, notice that French indirect objects are semantically similar to Belhare undergoers, which encode primarily beneficiaries rather than patients.) If the indirect object is a first or second person or a reflexive, 
Table 14. French verbal proclitic ordering

Subject $(j e, t u, i l$, nous etc. $)>$ Direct Object $(m e, t e$, le etc. $)>$ Locative $(y)>$ Partitive $(e n)$ $\uparrow$

Indirect Object

te, me, nous, vous, se

lui, leur

Table 15. French morphotactic eidemes

Clitics after direct object: Cilitics before direct objects:

$1>3$ je le lui ai dit $\quad 3>1 \quad$ il me l'a dit

$2>3$ tu le lui as dit $\quad 3>2 \quad$ il te l'a dit

$3>3$ il le lui a dit $\quad 3>3 \mathrm{REFL} \quad$ il se l'a dit

$1>2 \quad$ je te l'ai dit

$2>1 \quad$ tu me l'a dit

the clitic precedes the direct object marker, otherwise it follows (see Table 14). Notice that the morphemes are fully specified for role and reference. Their morphotactic behaviour is therefore redundant, i.e. predictable. That the first slot is the marked one is also consonant with language history. Up to the beginning of the 17th century, all indirect pronouns occupied a slot position after the direct object (Grévisse 1986: 1044f). The modern rule of proclitic placement divides participant configurations into two groups as shown in Table 15.

The motivation for the morphotactic eideme in Table 15 is based on the higher empathy degree of first and second person compared to a third person. This holds true also for reflexives in opposition to non-reflexives. As Kuno (1987: 154ff) has convincingly shown, these signs, especially if in indirect object function, very often imply high empathy with their referents. Their empathy degree is certainly higher than what non-reflexive third persons imply. In the kind of inversion observed in Belhare, the crucial criterion is whether the actor coincides with the empathy driven viewpoint. In French, by contrast, it is the propositional goal referent whose empathy status determines whether a scenario is "inverse" or "direct". For a nominative-accusative language like French, a goal referent, here the indirect object, is of lower referential prominence than an actor. The unmarked status is for a referen- 
Table 16. Paronymy in French indirect object proclitics

\begin{tabular}{|c|c|}
\hline $\begin{array}{l}m(\partial) \\
t(\partial)\end{array}$ & $\begin{array}{l}n u^{2} \\
v u^{2}\end{array}$ \\
\hline$l y i$ & lor \\
\hline
\end{tabular}

tially non-prominent category to match an empathetically non-prominent category, i.e. for an indirect object to be a third non-reflexive person. A scenario is marked when the two kinds of prominence mismatch, i.e. when high empathy forces a viewpoint from the referentially non-prominent indirect object. The scenario is then called "inverse". Notice however, that French inversion operates on a hierarchy closer to the one found in Plains Cree than to the one found in Belhare. As in Plains Cree, first and second person are not disentangled in inversion. French treats both scenarios as inverse. This pattern is independently motivated by the distribution of "to come" expressions, i.e. of verbs meaning inversion in space: venir is also used for motion towards the addressee, e.g. Demain, je viendrai chez toi.

The inversion principle in French gives not only rise to a position eideme but is also reflected by paronymy relations, i.e. by submorphemic phenomena. In inverse scenarios, proclitics have a parallel morpheme structure, which is $C(a)$ for singular and reflexive as against $C u^{z}$ for plural (see Table 16 , where the brackets indicate possible elision in allegro style; the superscript $z$ represents the liaison consonant). Notice that morpheme analysis would not allow an isolation of $-(\partial)$ and $-u^{2}$. These are, judged by the standards of Resonance Morphology, purely morphological resonances, i.e. eidemes. Although these eidemes are apparently well motivated, notice that there are also other items participating in this resonance (e.g., 3( ə) '1SG: S/A', $v u^{2}$ '2PL:S/A/U' and only marginally $n u^{z}$ '1PL:S/A/U', which has an allomorph $\gamma^{n}$ in $\mathrm{S}$ and A function.) It may well turn out, that there is some independent motivation at work here, but I shall not further belabour the issue. ${ }^{22}$ In any event, we have seen in Section four that eidemic phenomena often and naturally do exhibit non-motivated, "crazy" categories. 


\section{Conclusions}

In the preceding, we have observed that inversion motivates both supraand sub-morphemic eidemes. Interestingly, we find both patterns also in languages showing morphemic inversion, viz. in Plains Cree and $1 \mathrm{Cog}$-rtse rGya-ron. The eidemes relate the local scenarios $(1>2$ and $2>1)$, which rely on role and reference categories in both languages, to the direct and inverse morphemes. In lCog-rtse rGya-ron, the $2>1$ morpheme $k a w$ - is resonant to the inverse marker $w u \sim w$ - (e.g. tz-w-nasngo-n '2-INV-scold-2sG', i.e. 'S/he/they is/are going to scold you' - Nagano 1984: 70). This contrasts with the $1>2$ morpheme $t a$-. Consequently, while morpheme structure shows a neat distinction between local and non-local scenarios, eideme structure unifies them by an inversion-based resonance. A similar phenomenon can be observed in Plains Cree. The $i C(V)$ morpheme for $1>2$, -iti in the independent mode and it in the conjunct mode, is resonant to the inverse marker -ikw -iko that shows a similar structure on the skeleton tier. In contrast, the $2>1$ morpheme $i$ builds on the same phonological pattern as the direct morphemes, which all consist of a vowel only $(-a:,-e:)$. That Plains Cree eidemically relates $1>2$ to the inverse markers, and not to the direct markers is of course motivated by the $2>1>3(2>E>3)$ hierarchy that is independently referred to by person marking in the prefix slot (cf. rule (23b) above): independent of role, the prefix slot is filled with the person sign that ranks highest on this hierarchy. The $2>1$ and $1>2$ morphemes in Plains Cree are not only resonant to the direct and inverse markers, respectively, but they also share with them slot position. There is, thus, not only a phonological eideme but also a position eideme. The same is true for the Massachusett language (Goddard and Bragdon 1988) we considered briefly in the introduction. The inversion eideme found in both sub- and supramorphemic patterns of $2>1$ (-eh for ' $2 \mathrm{SG}>1 \mathrm{sG}$ ' and $-i$ for other number relations; cf. direct theme $-\hat{o}$ ) and $1>2$ signs (-ush for '1SG' and -un for anything else; cf. inverse theme $-u k w$ ) is, therefore, the ultimate solution of Humboldt's problem.

These observations call for a completion of Table 8 where Plains Cree morphemic inversion is compared to Belhare eidemic inversion. Table 17 puts together the contrasts and parallels in Belhare, lCog-rtse rGya-rôn and Plains Cree.

By introducing the theoretical tool of eidemes a whole area of research becomes accessible. Phenomena that, due to their non-semantic nature, lie 
Table 17. Contrasts and parallels between Belhare, lCog-rtse rGya-ron, and Plains Cree conjugation

\begin{tabular}{|c|c|c|}
\hline & morphemic structure & eidemic structure \\
\hline Belhare & role and reference & $\begin{array}{l}\text { direction and reference } \\
(1>2>3 \mathrm{SG}>3 \mathrm{NS})\end{array}$ \\
\hline lCog-rtse rGya-ron & $\begin{array}{ll}\text { local: } & \text { role and reference } \\
\text { non-local: } & \text { direction and reference } \\
& (1 / 2>3 \mathrm{SG}>3 \mathrm{NS})\end{array}$ & direction and reference $(1>2)$ \\
\hline Plains Cree & $\begin{array}{ll}\text { local: } & \text { role and reference } \\
\text { non-local: } & \text { direction and reference } \\
& (2 / 1>\text { prox. }>\text { obv. }>\text { f. obv. }\end{array}$ & $\begin{array}{l}\text { direction and reference }(2>1) \\
\text { t.) }\end{array}$ \\
\hline
\end{tabular}

beyond the scope of traditional morphemics can be captured in proper terms, that is in terms of motivation. The application of this theory has revealed that the marked nature of transitivity inversion may combine with other categories of referential markedness, e.g. with non-congruence of reference with illocutionary or predication structure. This suggests that motivations for eidemic patterns in verbal reference inflection may not be restricted to concepts of transitivity inversion. We have yet to explore and to determine the range of domains that motivates eidemic grouping of participant configurations. ${ }^{23}$

Authors's address:

Balthasar Bickel

Seminar für Allgemeine Sprachwissenschaft

Universität Zürich

Plattenstrasse 54

8032 Zürich

Switzerland 


\section{ABBREVIATIONS}

Morpheme glosses

$\begin{array}{llll}\text { A } & \text { actor } & \text { IPFV } & \text { imperfective } \\ \text { ADD } & \text { additive } & \text { IRR } & \text { irrealis } \\ \text { BEN } & \text { benefactive } & \text { NARR } & \text { narrative } \\ \text { CONF } & \text { confirmatory } & \text { NOML nominalizer } \\ \text { CONJ } & \text { conjunctive (Belhare); conjunct (Cree) } & \text { NPT } & \text { non-past } \\ \text { CONTR } & \text { contrastive } & \text { NS } & \text { non-singular } \\ \text { COP } & \text { copula } & \text { OBJ } & \text { (primary) object } \\ \text { DL } & \text { dual } & \text { OBV } & \text { obviative } \\ \text { DET } & \text { determinator } & \text { OPT } & \text { optative } \\ \text { DISC } & \text { discovery } & \text { PROX } & \text { proximative } \\ \text { DIST } & \text { distal } & \text { PT } & \text { past } \\ \text { DIR } & \text { direct } & \mathrm{Q} & \text { question } \\ \text { E } & \text { exclusive [+speaker }- \text { addressee] } & \text { S } & \text { subject (intransitive) } \\ \text { EXCL } & \text { exclamative } & \text { SS } & \text { same subject reference } \\ \text { I } & \text { inclusive [+speaker }+ \text { addressee] } & \text { TEL } & \text { telic } \\ \text { INAN } & \text { inanimate } & \text { TOP } & \text { topic } \\ \text { IND } & \text { independent } & \text { TR } & \text { transitive } \\ \text { INF } & \text { infinitive } & \mathrm{U} & \text { undergoer } \\ \text { INV } & \text { inverse } & \mathrm{X}>\mathrm{Y} & \mathrm{X} \text { acts on } \mathrm{Y} \\ \text { IMP } & \text { imperative } & {[-\mathrm{X}]} & \text { circumfix X }\end{array}$

Indices to disambiguate English glosses

$\begin{array}{ll}\text { d } & \text { dual } \\ \text { e } & \text { exclusive } \\ \text { f.obv } & \text { further obviative } \\ \text { i } & \text { inclusive } \\ \text { ns } & \text { non-singular }\end{array}$

$\begin{array}{ll}\text { obv } & \text { obviative } \\ \mathrm{p} & \text { plural } \\ \text { prox } & \text { proximative } \\ \mathrm{s} & \text { singular }\end{array}$

Symbols in the text and in tables
i, ii, iii
verb classes (Cree)
pf
prefix slot
sf
suffix slot
TAM tense, aspect, mood
$\Sigma \quad$ stem
$\sqrt{ }$ root
$\{\mathrm{X}, \mathrm{Y}\} \quad \mathrm{X}$ and $\mathrm{Y}$ are treated alike
[X] only used in context $\mathrm{X}$




\section{NOTES}

* I would like to thank the Deutsche Forschungsgemeinschaft for sponsering the initial fieldwork on Belhare in spring 1991 and the Max-Planck-Gesellschaft for further sponsering. I am indebted to Karen Ebert who introduced me to Kiranti linguistics and to Dhan Prasād Rāī who assisted my first steps in learning Belhare. Special thanks are due to Lekh Bahādur Rāi and his family in Belhārā, whose generous hospitality and continuing patience made the research a joyous one. I am also indebted to the staff of the Kośi Hills Development Programme, Dhankuța, who helped me a lot with logistic facilitations.

Parts of previous versions of the paper have been presented to the Seminar für Allgemeine Sprachwissenschaft der Universität Zürich in July 1991, to the Cognitive Anthropology Research Group at the Max Planck Institute for Psycholinguistics, Nijmegen, in October 1991 and to the Berner Zirkel für Sprachwissenschaft in April 1992. I wish to thank these audiences for stimulating discussions and useful comments. Furthermore, I am much indebted to Bernard Comrie, Sjors van Driem, Karen Ebert, Jane Simpson, Edgar Suter, David Wilkins and an anonymous Studies in Language referee for helpful comments and suggestions on an earlier draft of the present paper. I am, of course, alone responsible for all remaining flaws and mistakes.

1. Orthographic $<8>$ stands for a rounded mid-high back vowel phoneme that is realized as [u:] or [uw]. Massachusett is an extinct Algonquian language.

2. In Roman orthography I use $<\mathrm{t}, \mathrm{d}, \mathrm{r}>$ for the phonologically unmarked apico-alveolars and $<\mathrm{t}, \mathrm{d}>$ for their laminal counterparts in loan words. $<\mathrm{c}, \mathrm{j}>$ represent the affricates $/ \mathrm{ts}$, d/. Superscribed $h$ stands for a floating [+aspirated] feature. Where phonology deviates form morphological structure, I give both representations.

3. I shall not furthermore use the epithet "transitivity" that I have included in the title to avoid misunderstanding due to other notions of inversion (e.g. rule inversion, subjectindirect object inversion (dative subjects), etc.).

4. In the suffix strings, two morphophonological effects might blur immediate understanding: The $\{t\}$-suffix, which indicates non-past, is realized as a glottal stop before nasals. Subsequent consonants trigger an underspecified allomorph [-voice] for which they provide the slot to associate. Stem alternation results from predictable diphthongisation of the root's rime.

5. This analysis was indeed followed by Ebert (1991) and myself (Bickel 1991b).

6. In Bickel (1991a), I proposed a scale of convergence that ranges from near-ambiguity (paronymy) to non-ambiguity (Gesamtbedeutung). With integration of obligatorily resolved morpheme ambiguity, a revised version looks like the following:

Paronymy $>$ resolved polysemy $>$ amphiboly $>$ polysemy $>$ allosemy $>$ Gesamtbedeutung .

7. In this case, we would call -na a morpheme of cumulative exponence, not a portemanteau. The importance of this distinction is due to the late Meinrad Scheller, former Professor of General Linguistics at the University of Zürich. A similar distinction is proposed by Matthews (1974: 147) who calls portemanteau morphemes signs with "fused exponence". 
8. Actually, the pronoun unchik '3NS' would not resolve the notorious non-singular polysemy. However, the use of a demonstrative like nakhachi for dual or nakha for plural reference helps here.

9. The same holds for the supine or "purposive" marker -si 'in order to, for'.

10. On DeLancey's account, it would be the ergative case marker that signals the starting point (1981: 634). It is difficult to see how a role marker can consistently assign prominence. Indeed, judged alone by semantic role structure, an undergoer could easily qualify as "prominent" in the same way as an actor. "Prominence" as relevant to inversion is better seen as referential prominence linked to discourse topicality rather than to role.

11. I arbitrarily write ' $2 / 1$ ' instead of (to our view 'iconic') ' $1 / 2$ ' in deference to person and number marking in the prefix and suffix five slots (cf. rules in (23)). The hierarchical basis of inverse marking was already stated for Massachusett by Humboldt when he says "daß die beiden ersten Personen einen höheren Grad an Lebendigkeit vor der Phantasie des Volkes ausüben." (1836: 190). The combination of proximative vs. obviative with 2/1 vs. 3 follows Kuno's law on the transitivity of empathy relations (Kuno 1987: 207).

12. Cf. DeLancey (1980), Ebert (1990), and van Driem (1992) who draw on earlier work by Wen, Jin Péng and Nagano.

13. I concur with van Driem (1992: 49) in not synchronically splitting $t a$ - into $t z$ - ' 2 ' $+a$ - '?' (pace DeLancey (1980: 53f) and kaw- into ka- '?' + w- 'INV' (pace Ebert 1990: 58). Diachronically, however, a segmentation of $k a w$ - into $k a-$ ' 1 ' $+w$ - 'INV' makes sense in the light of an internal reconstruction $t a-$ ' $1>2$ ' $<* t a-$ ' 2 ' $+k z_{-}$' ' 1 ' (Nagano 1984: 72). The hypothesis is supported by the fact that $t a$ - has an allomorph [tok $\left.{ }^{\square_{-}}\right]$which is phonologically (!) conditioned by a subsequent velar stop. If the reconstruction proves to be correct, proto-rGya-ron would have to be analysed as building "local" configurations on direction and reference.

14. A problematic corollary of this terminological blending is found in Trubetzkoy (1934: 14) when he sets up special "Verbindungsmorpheme" to account for conjugation class resonances, which are predictable and semantically empty. In other traditions, such signs are explicitly referred to as "empty morphemes."

15. Much independent evidence in favour of Resonance Morphology, ranging from folk etymology and reanalysis to allusions and abbreviations, can be taken from Plank (1981), Hockett (1987: ch. 6) and Bybee (1985, 1988).

16. Viz. whether there is, in traditional terms, "homonymy" or "polysemy" at work. For a critique of these concepts, cf. Bickel (1991a: 18f).

17. The indexical function of alternations has been pointed out by a number of scholars, in particular Komárek (1964), Anttila (1975) and Andersen (1980). Such a view is obviously in parallel with locating the function of allophony in a security device for decodability, a theory that has often been claimed (e.g. by Jakobson and Waugh (1979: 36ff) or Hockett (1987: 62f)).

18. To illuminate this a little bit more, we may think of the contrast between form as a supple attribute of an important content like clothes and form as a characteristic structure like the shape of a statue. In Greek philosophy, this contrast is sometimes referred to by the opposition of morphê and eídos. Obviously, traditional morphology is mostly concerned 
with the cognate of the etymon in the name "morphology" itself, rather than with eidos, i.e. with eidemes. Another analogy may be drawn from art. Whereas cubism is in some sense the perfection of handling content, it was up to the Stijl and Bauhaus movements to focus on form in itself. It does not come as a surprise, then, that one of the leading proponents of consequent morpheme analysis, Roman Jakobson, had strong affinities with cubism (cf. Holenstein 1975: 49f).

19. The idea of "extra-morphological motivation" is partly due to Wurzel (1992). Bybee (1985) suggests "iconic diagrammaticity" to account for similar phenomena motivation is designed to account for. While this might be the result of a cross-linguistic study (as her work suggests), it cannot of course be part of the morphological theory within which such a study is conducted.

20. Not surprisingly, the difference of eidemic and morphemic gender resumes in a semiotic morphology the distinction between noun classes and noun classifiers. Three kinds of "gender" have to be distinguished: Eidemic gender (declension classes in Indo-European or lexical noun classes in Bantu, also cf. Whorf 1945 [1956: 99]), syntactic gender (modifier or verb agreement) and 'irregular' morphemic gender (noun class shift by "disagreement", functionally like classifiers but usually not operating in a noun phrase domain).

21. On motivation in syntax see Bickel (1991a: $14 \mathrm{f}$ et passim), where a distinction is drawn between syntactic function (the meaning of a construction) and its extra-syntactic motivation.

22. One might speculate, for example, on the special status of $v u^{z}$, which is also used as an honorific.

23. For an attempt in this direction see Bickel 1992.

\section{REFERENCES}

Andersen, Henning. 1980. "Morphological change: Towards a typology". In: Fisiak, Jacek (ed.), Historical morphology. The Hague: Mouton.

Anttila, Raimo. 1975. The indexical element in morphology. Innsbruck: Universität [Innsbrucker Beiträge zur Sprachwissenschaft 12].

Anttila, Raimo. 1989. Historical and comparative linguistics. Amsterdam: Benjamins [Second revised edition].

Bickel, Balthasar. 1991a. Typologische Grundlagen der Satzverkettung. Ein Beitrag zur allgemeinen Grammatik der Satzverbindung und des Fährtenlegens. Zürich: Universität [Arbeiten des Seminars für Allgemeine Sprachwissenschaft 9].

Bickel, Balthasar. 1991b. "From morphemics to Gestalt morphology: Some reflections with particular reference to Belhare". Paper presented to the Cognitive Anthropology Research Group Nijmegen, October 1991. 
Bickel, Balthasar. 1992. "Motivations of scenario classes: Belhare and Kham". Paper presented at the 25th International Conference on Sino-Tibetan Languages and Linguistics, Berkeley, October 14-18.

Bolinger, Dwight L. 1948. "On defining the morpheme". Word 4: 18-23.

Bolinger, Dwight L. 1950. "Rime, assonance, and morpheme analysis". Word 6: 117-36.

Bühler, Karl. 1934. Sprachtheorie. Die Darstellungsfunktion der Sprache. Stuttgart: Fischer.

Bybee, Joan. 1985. Morphology. A study of the relation between form and meaning. Amsterdam: Benjamins.

Bybee, Joan. 1988. "Morphology as lexical organization". In: Hammond, Michael; and Noonan, Michael (eds), Theoretical morphology. Approaches in modern linguistics. San Diego: Academic.

Carstairs, Andrew. 1987. Allomorphy in inflexion. London: Croom Helm.

Dahlstrom, Amy Louise. 1986. Plains Cree morphosyntax. University of California Ph. D. dissertation. Ann Arbor: University Microfilms International.

DeLancey, Scott. 1980. Deictic categories in the Tibeto-Burman verb. Indiana University $\mathrm{Ph}$. D. dissertation. Ann Arbor: University Microfilms International.

DeLancey, Scott. 1981. "An interpretation of split ergativity and related patterns". Language 57: 626-57.

Derwing, Bruce L.; and Skousen, Royal. 1989. "Morphology in the mental lexicon: A new look at analogy". Yearbook of Morphology 2: 55-71.

Dressler, Wolfgang U. 1985. Morphonology: The dynamics of derivation. Ann Arbor: Karoma.

Driem, George van. 1987. A grammar of Limbu. Berlin: Mouton de Gruyter.

Driem, George van. 1991. "Tangut verbal agreement and the patient category in Tibeto-Burman". Bulletin of the School of Oriental and African Studies 54: 520-34.

Driem, George van. 1992. "Le proto-kiranti revisité: Morphologie verbale du lohorung”. Acta Linguistica Hafniensia 24: 33-75.

Ebert, Karen H. 1987. "Grammatical marking of speech act participants". Journal of Pragmatics 11: 473-82.

Ebert, Karen H. 1990. "On the evidence for the relationship Kiranti-Rung”. Linguistics of the Tibeto-Burman Area 13: 57-78.

Ebert, Karen H. 1991. "Inverse and pseudo-inverse prefixes in Kiranti languages: Evidence from Belhare, Athpare and Dungmali". Linguistics of the Tibeto-Burman Area 14: 73-92. 
Ehrenfels, Christian von. 1890. "Über 'Gestaltqualitäten'”. Vierteljahrsschrift für wissenschaftliche Philosophie 14: 249 - 92 [Reprinted in Philosophische Schriften, Band 3: Psychologie, Ethik, Erkenntnistheorie. Ed. Reinhard Fabian, München: Philosophia 1988].

Ertel, Suitbert; and Bloemer, Wolf-Dietrich. 1975. "Affirmation and negation as constructive action". Psychological Research 37: 335-42.

Foley, William A.; and Van Valin, Robert D. 1984. Functional syntax and universal grammar. Cambridge: University.

Goddard, Ives. 1974. "Remarks on the Algonquian independent indicative". International Journal of American Linguistics 40: 317-27.

Goddard, Ives; and Bragdon, Kathleen J. 1988. Native writings in Massachusett. Philadelphia: American Philosophical Society.

Goffman, Erving. 1979. "Footing". Semiotica 25: 1-29.

Grévisse, Maurice. 1986. Le bon usage. Douzième édition refondue par André Goosse. Paris: Duculot.

Heath, Jeffrey. 1976. "Substantival hierarchies: Addendum to Silverstein". In: Dixon, R. M. W. (ed.), Grammatical categories in Australian languages. Canberra: Australian Institute of Aboriginal Studies.

Heath, Jeffrey. 1991. "Pragmatic disguise in pronominal-affix languages". In: Plank, Frans (ed.), Paradigms. The economy of inflection. Berlin: Mouton de Gruyter.

Hockett, Charles F. 1958. A course in modern linguistics. New York: Macmillan

Hockett, Charles F. 1966. "What Algonquian is really like". International Journal of American Linguistics 32: 59-73.

Hockett, Charles F. 1987. Refurbishing our foundations. Elementary linguistics from an advanced point of view. Amsterdam: Benjamins.

Hodgson, Brian Houghton. 1856. "Aborigines of the Nilgiris, with remarks on their affinities". Journal of the Asiatic Society of Bengal 25: 498-522 [Also in Hodgson, Brian Houghton. 1880. Miscellaneous essays relating to Indian subjects, vol. II. Reprint New Delhi: Asian Educational Services 1992].

Holenstein, Elmar. 1975. Roman Jakobsons phänomenologischer Strukturalismus. Frankfurt a. M.: Suhrkamp.

Humboldt, Wilhelm von. 1836. Über die Verschiedenheit des menschlichen Sprachbaus und ihren Einfluss auf die geistige Entwickelung des Menschengeschlechtes. Berlin: Dümmler [Reprinted by Dümmler 1960].

Husserl, Edmund. 1913. Logische Untersuchungen, 2. Band, 1. Teil: Untersuchungen zur Phänomenologie und Theorie der Erkenntnis. Halle: Niemeyer [Second revised edition]. 
Jakobson, Roman; and Waugh, Linda R. 1979. The sound shape of language. Bloomington: Indiana University.

Komárek, Miroslav 1964. "Sur l'appréciation fonctionelle des alternances morphonologiques". Travaux linguistiques de Prague 1: 145-61.

Kuno, Susumu. 1987. Functional syntax. Anaphora, discourse and empathy. Chicago: University.

Lakoff, George. 1977. "Linguistic Gestalts". In: Beach, Woodford A.; Fox, Samuel E.; and Philosoph, Shulamith (eds), Papers from the thirteenth regional meeting of the Chicago Linguistic Society, April 14 - 16, 1977. Chicago: University.

Levinson, Stephen C. 1988. "Putting linguistics on a proper footing: Explorations in Goffman's concepts of participation". In: Drew, Paul; and Wootton, Anthony (eds), Erving Goffman: exploring the interaction order. Cambridge: Polity.

Marty, Anton. 1908. Untersuchungen zur Grundlegung der allgemeinen Grammatik und Sprachphilosophie, 1. Band. Halle: Niemeyer.

Matthews, P. H. 1974. Morphology. An introduction to the theory of wordstructure. Cambridge: University.

Merleau-Ponty, Maurice. 1945. Phénoménologie de la perception. Paris: Gallimard.

Nagano, Yasuhiko. 1984. A historical study of the rGyarong verb system. Tokyo: Seishido.

Plank, Frans. 1981. Morphologische (Ir-)Regularitäten. Aspekte der Wortstrukturtheorie. Tübingen: Narr.

Plank, Frans. 1991a. "Of abundance and scantiness in inflection: A typological prelude". In: Plank, Frans (ed.), Paradigms. The economy of inflection. Berlin: Mouton de Gruyter.

Plank, Frans. 1991b. "Rasmus Rask's dilemma”. In: Plank, Frans (ed.) Paradigms. The economy of inflection. Berlin: Mouton de Gruyter.

"Projet de terminologie phonologique standardisée". Travaux du cercle linguistique de Prague 4 (1931): 309-23.

Rock, Irvin; and Palmer, Stephen. 1990. "The legacy of Gestalt psychology". Scientific American 263, 6: 48-61.

Sapir, Edward. 1921. Language, an introduction to the study of speech. New York: Harcourt, Brace \& Co.

Silverstein, Michael. 1976. "Hierarchy of features and ergativity". In: Dixon, R. M. W. (ed.) Grammatical categories in Australian languages. Canberra: Australian Institute of Aboriginal Studies. 
Trubetzkoy, Nikolay Sergeevič. 1934. "Das morphonologische System der russischen Sprache (Description phonologique du russe moderne II)". Travaux du cercle linguistique de Prague 5, 2.

Whorf, Benjamin Lee. 1945. "Grammatical categories". Language 21: 1-11. [Also in Caroll, John B. (ed.), Language, thought, and reality. Selected writings of Benjamin Lee Whorf. Cambridge, Mass.: MIT 1956]

Wierzbicka, Anna. 1988. The semantics of grammar. Amsterdam: Benjamins [Studies in Language Companion Series 18]

Wolfart, H. Christoph. 1973. Plains Cree: A grammatical study. Philadelphia: American Philosophical Society [Transactions of the American Philosophical Society - New Series 63, 5].

Wolfart, H. Christoph. 1978. "How many obviatives: Sense and reference in a Cree verb paradigm". In: Cook, Eung-Do; and Kaye, Jonathan (eds), Linguistic studies of native Canada. Vancouver: University of British Columbia.

Wurzel, Wolfgang Ullrich. 1989. Inflectional morphology and naturalness. Dordrecht: Kluwer.

Wurzel, Wolfgang Ullrich. 1992. "Flexionsmerkmale". Paper presented at the 14th Annual Meeting of the Deutsche Gesellschaft für Sprachwissenschaft, Bremen, February 26-28. 
Apart from its representational meaning, the optative has a semantic component on the appeal dimension of speech (Bühler's (1934) terminology). Unlike an imperative, where the speaker wants to interfere directly in the subject's actions, the optative entitles an intermediary to substitute as controller of the event. This intermediary is an instance distinct from the verb's subject referent, i.e. from the ultimate illocutionary target. Being a semantic property, this holds true also for second person optatives. Thus, a form like (45a) cannot mean 'May you understand!'. It can only report an optative. A paraphrase of (45a) would use the unmarked subjunctive form (45b) rather than an imperative (45c).

a. ak-tupt-u-ga.

OPT-understand-3U-2

'You may want to understand.'

b. tuptuga hola.

tupt-u-ga

understand-3U-2 probably

'You may understand.' c. tuptu!

tupt-a- $u$

understand-IMP-3U

'You should understand!'

Likewise, (46a) does not mean that the speaker wants the addressee to get wet, but rather that the speaker thinks that the addressee did not oppose getting wet in an imagined optative act. It is thus similar to (41) and (44) and its discourse structure is in parallel with an explicit form for reporting speech (46b).

a. ak-wayuk-ga.

OPT-get_wet-2

'Looks as if you want to get wet.' [said to somebody going for

a hike without umbrella although it started to rain.]

b. ak-lur-u-gak-phu.

OPT-tell-3U-2-NARR

'You may tell it to him, they say' / 'You are to tell it to him.'

Non-second-person hortatives or optatives necessarily distinguish between an intermediary, the current addressee, and an ultimate illocutionary target, the verb's subject (cf. Levinson 1988: 188). The Belhare optative has turned this communicative rule into semantics. The combination of this property with the representational meaning of the optative has the effect that 